NBER WORKING PAPER SERIES

\title{
THE EFFECTS OF HOUSING ASSISTANCE ON LABOR SUPPLY: EVIDENCE FROM A VOUCHER LOTTERY
}

\author{
Brian A. Jacob \\ Jens Ludwig \\ Working Paper 14570 \\ http://www.nber.org/papers/w14570
NATIONAL BUREAU OF ECONOMIC RESEARCH
1050 Massachusetts Avenue
Cambridge, MA 02138
December 2008

This paper is part of a larger series of studies of housing vouchers in Chicago with Greg Duncan, Michael Johnson, James Rosenbaum and Jeffrey Smith. Generous financial support was provided by the National Consortium on Violence Research, the Northwestern University / University of Chicago Joint Center for Poverty Research, the Smith Richardson Foundation, the William T. Grant Foundation, a HUD Urban Studies Postdoctoral Fellowship (to Jacob) and a Brookings Institution post-doctoral fellowship sponsored by the Andrew W. Mellon Foundation (to Ludwig). We thank John Baj, Ken Coles, Robert Goerge, Ron Graf, Anjali Gupta, Barry Isaacson, Bong Joo Lee, Lucy Mackey Bilaver, Jennifer O'Neil, Todd Richardson and William Riley for their assistance in obtaining and interpreting the data used in this study. Thanks to Joe Doyle, Susan Dynarski, Amy Finkelstein, Jeffrey Liebman, Erzo Luttmer, Ben Olken, Edgar Olsen, Barbara Schone, seminar participants at the Association for Public Policy Analysis and Management, the Bureau of Labor Statistics, the Chicago Federal Reserve, Harvard, and particularly Jeffrey Kling for helpful comments. Thanks to Dave Kirk, Sarah Rose, Elias Walsh, Wei Ha, Josh Hyman and Thomas Wei for excellent research assistance. Any errors and all opinions are of course our own. The views expressed herein are those of the author(s) and do not necessarily reflect the views of the National Bureau of Economic Research.

NBER working papers are circulated for discussion and comment purposes. They have not been peerreviewed or been subject to the review by the NBER Board of Directors that accompanies official NBER publications.

(C) 2008 by Brian A. Jacob and Jens Ludwig. All rights reserved. Short sections of text, not to exceed two paragraphs, may be quoted without explicit permission provided that full credit, including (C notice, is given to the source. 
The Effects of Housing Assistance on Labor Supply: Evidence from a Voucher Lottery Brian A. Jacob and Jens Ludwig NBER Working Paper No. 14570

December 2008

JEL No. I38,J22

\begin{abstract}
$\underline{\text { ABSTRACT }}$
This study estimates the effects of means-tested housing programs on labor supply using data from a randomized housing voucher wait-list lottery in Chicago. Evidence for the net effects of housing programs on labor supply is central to a wide range of policy decisions about how to provide housing assistance to the poor. Economic theory is ambiguous about the expected sign of any labor supply response. We find that among working-age, able-bodied adults, housing voucher use reduces quarterly labor force participation rates by 4 percentage points ( 6 percent of the control complier mean) and quarterly earnings by $\$ 285$ (10 percent), and increases social program participation rates by 2 percentage points (16 percent of the control mean). These impacts are toward the lower end of the range of recent estimates from other studies of housing programs, but nonetheless do still imply that housing vouchers reduce labor supply.
\end{abstract}

Brian A. Jacob

Gerald R. Ford School of Public Policy

University of Michigan

735 South State Street

Ann Arbor, MI 48109

and NBER

bajacob@umich.edu

Jens Ludwig

University of Chicago

1155 East 60th Street

Chicago, IL 60637

and NBER

jludwig@uchicago.edu 


\section{INTRODUCTION}

In 2005 the federal government spent $\$ 25.5$ billion on housing assistance for the poor, slightly more than combined federal and state spending on TANF. ${ }^{1}$ Understanding how housing assistance affects the behavior of recipients is relevant for policy decisions about how best to help poor people with their housing needs, including the optimal design of housing programs and the question of whether to address housing problems among the poor through housing programs at all. Yet the research literature on the behavioral effects of housing programs is, in the words of one leading housing economist, "shockingly small" (Olsen, 2003, p. 366).

The lack of good empirical evidence on this topic is particularly unfortunate because economic theory yields ambiguous predictions about the sign, much less the magnitude, of any labor supply response to means-tested housing programs. The standard static labor supply model predicts housing programs should reduce labor supply through income and substitution effects. However, the effects of in-kind transfers depend on how the program constrains consumption, and whether the subsidized good is a complement or substitute to leisure (Murray, 1980, Leonesio, 1988, Moffitt, 2002, Shroder, 2002). Some analysts claim housing programs may be work-neutral, or even increase work, by reducing the price of complements to work such as residential stability, improved housing or neighborhood quality, or proximity to jobs.

Existing estimates for the effects of means-tested housing assistance on labor supply are limited and mixed. One widely cited review argues "housing assistance is not persuasively associated with any effect on employment" (Shroder, 2002, p. 381, 410). But absent a clear source of exogenous identifying variation, selection bias remains a serious concern with nearly all prior studies. The one randomized experiment in this area finds that so-called Welfare to Work (WtW) housing vouchers reduce labor supply, although apparently just for the first year following random assignment, while also causing a large, persistent increase in TANF receipt (Gubits et al., 2006). While the $\mathrm{WtW}$ experiment has a strong research design, its external validity may be limited because eligibility for the program was restricted to TANF recipients for whom local housing agencies decided vouchers were "critical" to their labor market success.

In this paper, we estimate the effects of means-tested housing assistance on labor supply using a unique dataset of all applicants for Section 8 housing vouchers in Chicago during the late

1 Total spending on TANF was $\$ 25.4$ billion. Total spending on housing programs for low-income households by the U.S. Department of Housing and Urban Development equaled \$23.1 billion, and the U.S. Department of Agriculture spent approximately $\$ 2.4$ billion for such programs. 
1990s. Our identification strategy takes advantage of the fact that housing assistance, unlike many other social programs, is not an entitlement, and so benefits are rationed. When the

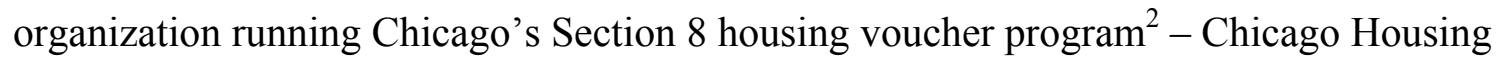
Authority Corporation, Inc. (CHAC) - constituted a new waiting list for the program in July, 1997, a total of 82,607 income-eligible families applied to CHAC for housing vouchers - far more than the number of vouchers available. As a fair way to allocate vouchers in the presence of excess demand, CHAC randomly assigned each applicant a position on the waiting list. By 2003, roughly 18,110 families had been offered a voucher.

We focus on the roughly 90 percent of CHAC voucher applicants living in private-market housing at the time they applied, for whom vouchers increase housing consumption, disposable income and marginal tax rates. In this way, our analysis is very different from the Moving to Opportunity (MTO) experiment, which offered vouchers to families living in public housing. For the MTO program population, housing vouchers will not directly affect income or wage rates (because the program rules for housing vouchers and public housing are similar), but do generate large changes in neighborhood environments (Kling, Liebman and Katz, 2007). Hence, MTO tells us something about the effects of changing the type of housing assistance provided to lowincome families (vouchers versus public housing), and more generally helps shed light on the importance of neighborhood effects on behavior and well-being. Our study instead estimates the effects of expanding the set of people receiving housing assistance by issuing more vouchers.

The primary contribution of our paper is to provide what we believe are the first estimates of the effects of a very large and understudied social program - housing vouchers - on labor supply that rely on both a clearly exogenous source of identifying variation and a fairly representative sample of program participants. Our analytic sample consists of the entire population of families who applied for housing vouchers in Chicago in the late-1990s. We find that for working-age, able-bodied adults, voucher use reduces quarterly employment rates by nearly 4 percentage points ( 6 percent) and quarterly earnings by $\$ 328$ (11 percent), and increases TANF receipt by 2 percentage points (16 percent). Unlike with the $\mathrm{WtW}$ voucher experiment,

2 For many years, federal rental subsidy programs included both a voucher and a certificate program. The main difference was that the voucher program allowed families to lease units with rents above the Fair Market Rent, although families could not pay more than a certain share (usually 40 percent) of income towards rent. Recently both programs have been combined into the Housing Choice Voucher program. For convenience, we refer to rental subsidies in our analysis simply as "Section 8 vouchers," which is how most of the CHAC families knew the program. 
the labor supply impacts we estimate seem to persist. We also see some slight increase in average labor supply for those families who expect to receive a voucher in the future, consistent with predictions from the lifecycle labor supply model that people may shift work effort towards periods when their net wage is relatively higher. We also find that that housing vouchers seem to have little effect on two of the key housing-specific mechanisms hypothesized to boost employment: the presence of employed or otherwise affluent neighbors (who might provide useful job references or otherwise be supportive of work) and residential stability (although we note that vouchers do seem to change slightly the timing of moves, as families who expect to receive a voucher delay moves until their voucher offer).

If it is true that the primary mechanisms through which housing vouchers affect labor supply are standard income and substitution effects, then our findings may have broader implications about how people respond to means-tested transfers more generally. Because both the income and substitution effects induced by housing vouchers should reduce labor supply, our reduced-form impacts enable us to bound the size of each effect. Our bounds suggest income and substitution elasticities that are much smaller than most earlier non-experimental studies of single mothers, but are consistent with those from the Negative Income Tax experiments.

Section II discusses the behavioral mechanisms through which vouchers might affect labor supply. Sections III and IV review the prior literature and describe the Chicago voucher lottery that we study. Sections V and VI discuss our data and empirical strategy. Finally, we present our findings and discussion in sections VII and VIII.

\section{HOUSING VOUCHERS}

In this section, we provide a brief review of the housing voucher program rules and how vouchers might affect labor supply; for a more detailed discussion, see Appendix A. Housing vouchers subsidize low-income families to live in private-market housing. Eligibility limits for housing programs are a function of family size and income. Since 1975, an increasing share of housing assistance has been devoted to households with incomes below 50 percent of the local median. Yet, demand far exceeds supply. Only 28 percent of renters with incomes below 50 percent of the local median receive housing assistance (Olsen, 2003). The maximum subsidy available to families is governed by the Fair Market Rent (FMR), which was equal to the $45^{\text {th }}$ percentile of the local private-market rent distribution up through 1995 , then lowered to the $40^{\text {th }}$ percentile. Since 2001, selected metropolitan areas, including Chicago, were allowed to set 
FMR at the $50^{\text {th }}$ percentile. The FMR for a two-bedroom apartment in Chicago was equal to $\$ 699$ in 1994, \$732 in 1997, and \$762 in 2000 (in nominal dollars). The voucher subsidy equals the difference between the family's rent contribution (30 percent of adjusted income) and the lesser of either FMR or the unit rent. Families with vouchers can keep the subsidy basically for as long as they stay income eligible, which for our sample should be quite some time: average baseline income in our sample was $\$ 14,000$, while the subsidy phase out range is $\$ 43,000$ (unless otherwise noted, all figures are reported in 2007 dollars).

Many families who are offered vouchers do not use them (Olsen, 2003). There are several candidate explanations for the limited take-up rates. Many housing units have rents above the voucher program's FMR. Some landlords may not want to deal with the voucher program's requirements on paperwork or minimum quality, which are verified by inspection although failed units can be modified and re-inspected. And families offered vouchers have a limited amount of time to lease a unit (usually 3 to 6 months).

The most obvious way in which housing voucher receipt might affect labor supply is through the substitution and income effects implied by the standard static labor supply model illustrated in Figure I. The budget constraint for families who do not receive housing assistance is given by $\mathrm{ADE}$, with slope equal to minus one times the individual's market wage (w). The maximum subsidy for a family with no earnings is the value of the FMR (given by G), which for the typical CHAC applicant is equal to around $\$ 12,000$ per year. Voucher rules require participants to pay 30 percent of their (adjusted) income towards rent, which reduces the aftertax wage of voucher recipients. The amount of this "tax" will be smaller for families receiving other social benefits given the way the various program rules interact (see Appendix A). The subsidy value for families with labor market earnings (given by B in Figure I) will be less than the full amount of the FMR, but as discussed below, the average voucher subsidy is still extremely large relative to most means-tested transfer programs.

Predicting the effect of housing programs on work is complicated for at least two reasons. The first involves how the dynamics of these programs relate to the life-cycle model of labor supply (see for example MacCurdy, 1981). In many cities, housing programs have very long waiting lists. Families on the wait list expect to receive a subsidy in the future, which increases lifetime permanent income. But these families also know that once they receive a voucher, their wage rate will be reduced because of the implicit tax. If people wish to supply more labor in 
periods when wages are high and intertemporal substitution effects dominate lifetime wealth effects, we could observe an increase in work effort while they are on the program wait list.

Second, and perhaps more importantly, the in-kind nature of the subsidy makes it is hard to predict the effects of housing vouchers on labor supply. The effect on labor supply will depend in part on the degree to which the in-kind subsidy constrains people's consumption, and how the subsidized commodity complements or substitutes for leisure (Murray, 1980, Leonesio, 1988, Moffitt, 2002). If the subsidized good is a complement to leisure, then the transfer program will lead to an unambiguous decrease in work effort. If the subsidized good is a substitute for leisure, the transfer will lead to a smaller reduction in work effort than an equally generous cash transfer. ${ }^{3}$ In principle, the transfer could increase work effort (Leonesio, 1988). ${ }^{4}$

\section{PREVIOUS EVIDENCE}

Whether and how means-tested housing programs impact work effort is ultimately an empirical question. In an influential review of the housing literature, Mark Shroder (2002) laments the "critical theoretical weaknesses" of the standard labor supply model in ignoring the possibility that increased housing consumption could help increase work, and argues the empirical research is "consistent with [a housing voucher] ... effect of zero" on labor supply. However, Shroder notes that most studies simply compare the labor supply of program participants with non-participants, which may confound program impacts with unmeasured individual attributes associated with both work decisions and program participation. In addition, many studies measure program participation using survey self-reports, which suffer from reporting problems that vary systematically by actual program involvement. ${ }^{5}$

More recent studies subsequent to Shroder's review also paint a mixed picture of whether

\footnotetext{
3 In the case of housing, it is not clear whether one should regard the commodity as a substitute or complement for leisure. More or better housing may promote work by reducing exposure to environmental toxins, improving sleep, enabling people to have a consistent residential address or live in an area that is closer to jobs or employed neighbors (Kain, 1968), or have lower crime rates. On the other hand, better housing may complement leisure, since it is more pleasurable to spend time in a nicer space.

4 Schone (1992) shows that the non-linearities housing vouchers generate in budget constraints could also potentially increase work effort. The basic intuition is that housing programs offer participants a "take it or leave it" level of housing consumption. If housing program participation increases the amount that people contribute out-ofpocket towards housing, the result could be an increase in work effort in order to meet minimal levels of consumption for other goods.

5 In a recent paper, Hoynes and Schanzenbach (2007) exploit county-level variation in the timing of the original implementation of the Food Stamps Program to estimate the impact of this in-kind transfer on consumption and labor supply. While their labor supply estimates are rather imprecise, they find evidence that the program generates small work disincentive effects, roughly consistent with the magnitude of those found in the NIT experiments.
} 
housing programs impact labor supply. Yelowitz (2001) exploits across-area variation in FMRs and housing program rules that relate housing benefits provided by either public housing or housing vouchers to the sex composition of a family's children. Yelowitz finds a one standard deviation increase in housing subsidy ( $\$ 180$ per month) reduces labor force participation by 4 percentage points (from a baseline of 70-75 percent). It is not clear, however, how much of the identification comes from variation in benefit levels due to the sex composition of children, which is plausibly exogenous, versus within- and/or across-MSA changes in FMR or income eligibility limits, which may be correlated with unobserved factors that affect labor supply.

A more common estimation approach among recent studies is to rely on within-person over-time variation in housing program participation and labor supply. Olsen et al. (2005) use data from the Panel Study of Income Dynamics (PSID) and find a 30 to 35 percent reduction in earnings associated with receiving either a housing voucher or a project-based subsidized housing unit. In contrast, Newman, Holupka and Harkness (forthcoming) use propensity-score matching methods with the PSID and find no detectable effects of entering project-based assistance on work or earnings, but find welfare receipt increases by over 50 percent. Using a similar propensity-score matching design, Susin (2005) finds housing assistance reduces earnings by 15 percent among respondents to the Survey of Income and Program Participation, and Carlson et al. (2008) find earnings drop 12 percent the first year following voucher receipt using administrative data from Wisconsin, although the effect fades out within five years.

The recent Welfare-to-Work (WtW) experiment by HUD suggests vouchers reduce quarterly employment rates (earnings) by 5 to 7 (12) percent the first year of the demonstration (Gubits et al., 2006). The estimated impacts are not statistically significant during years two and three, but the confidence intervals cannot rule out impacts on work and earnings of up to 10 and 19 percent, respectively. The authors argue that the short-term decline in work is due to temporary disruptions from moving. But at the same time, the WtW study does find that vouchers generate large, sustained increases in TANF receipt.

The main limitation with the $\mathrm{WtW}$ voucher experiment has to do with external validity. The sample is restricted to families who are receiving TANF at baseline, a program that, as noted above, mutes the effect of voucher receipt on effective marginal tax rates. Of course, having results applicable to just TANF recipients would still be useful, despite the large decline over time in TANF receipt rates. But eligibility for WtW was further limited to the subset of TANF 
recipients for whom vouchers were, in the judgment of housing officials, "critical to the families' ability to obtain or retain employment" (Gubits et al., 2006, p. 7). Thus the degree to which these findings generalize to the broader population of housing program participants is not clear.

\section{THE CHICAGO HOUSING VOUCHER LOTTERY}

In July 1997, Chicago Housing Authority Corporation (CHAC) opened the city's voucher wait list for the first time in 12 years, and received a total of 82,607 applications from incomeeligible people. CHAC randomly assigned applicants to a waiting list in August 1997, and notified those in the top 35,000 positions of their wait list number. CHAC told these families on the "active wait list" that they would be offered a voucher within three years. CHAC informed the remaining applicants (random lottery numbers 35,001 to 82,607) that they would not receive vouchers. About 4,625 families were offered vouchers in the first year after the wait-list lottery. Service of the July 1997 wait list was interrupted in August 1998, as CHAC was required to provide vouchers to a set of Latino families in response to a discrimination lawsuit against the City of Chicago. CHAC began to serve the 1997 wait list again at the start of 2000. By May 2003, after offering vouchers to 18,110 families from this original 1997 waiting list, CHAC was "over-leased" and essentially stopped offering any new vouchers. ${ }^{6}$

In the analysis that follows, we define our "treatment group" to be families offered vouchers by May 2003 (lottery numbers 1 to 18,110). The control group consists of those applicants with lottery numbers above 35,000 who were told that they were not on the active wait list and would not get a voucher. In our main analyses we exclude from our sample those families with lottery numbers between 18,110 and 35,000 because of their ambiguous treatment status (i.e., their behavior might have been affected by the anticipation of a voucher, but since CHAC stopped giving out vouchers in 2003, these families may have given up hope of getting one). We later show that including this group does not change our findings.

\section{DATA AND SUMMARY STATISTICS}

This section briefly describes the primary data sources used in our analysis. For more details, see Appendix C. The application forms for the 1997 wait list provide baseline information on the 82,607 adults and nearly 8,700 spouses who applied to CHAC for a housing

6 That is, CHAC had issued as many or more vouchers than it had funding to pay for. CHAC sent a letter to all families still on the wait list asking them to verify their address and interest in receiving a voucher. Roughly 9,300 families responded. In a follow-up letter, CHAC indicated families with numbers from 18,110 to 20,853 should expect to wait at least one year; numbers between 20,854 and 27,455 at least two years; 27,457 to 33,902 at least three years and the remainder at least four years. (Personal communication with Ken Coles, CHAC, on 4/8/2004). 
voucher. These files include information on address, lottery number and basic household demographics, as well as identifying information for the household heads and spouses. The baseline application forms do not include identifying information on other members of the applicant's household. We use data from the Illinois Department of Human Services (IDHS) to determine who lived with the CHAC applicants in the period immediately before the wait list was opened. Because this procedure (described in Appendix B) relies entirely on pre-lottery data, any measurement error in identifying baseline household members will be orthogonal to wait list position. Data on voucher utilization comes from HUD 50058 records, which families must complete at least once each year to verify program eligibility.

To track residential locations for both the treatment and control groups we rely on a variety of passive tracking sources such as the National Change of Address (NCOA) registry and national credit bureau checks. Because of resource constraints, we tracked a random ten percent sub-sample of all CHAC applicants. ${ }^{7}$ Using these addresses, we are able to characterize each household's residential neighborhood using (among other sources) 2000 census data down to the block group level. To determine whether a family was in public housing or project-based Section 8 housing (essentially privately-operated public housing) at the time of the lottery, we merge baseline addresses from the lottery application files to lists of subsidized units maintained by the Chicago Housing Authority and HUD. ${ }^{8}$

To obtain measures of labor force participation, we merge the applicants to several different Illinois state administrative databases using probabilistic matching techniques that use data on name, date of birth and social security number. Illinois Unemployment Insurance (UI) records from 1990 through the end of 2005 provide quarterly earnings for individuals working for employers who pay more than $\$ 1,500$ in total wages in a quarter to all employees, but excludes those who work for themselves, the military or other branches of the federal

\footnotetext{
7 We have confirmed that this subset matches the overall applicant pool on a variety of baseline characteristics, and that the impact estimates on labor supply for this 10 percent sub-sample are virtually identical to the impact estimates for the full sample. We are also able to (at least partially) verify the accuracy of the passive tracking techniques using the subset families that received housing vouchers. In the vast majority of these cases, the location information obtained through passive tracking matches the information found in the administrative 50058 records. 8 Throughout our analysis, we focus on baseline housing status because the outcome of the voucher lottery may have influenced a family's living arrangement. This means the group identified as living in a housing project at baseline may include some families who are in private-market housing by the time they are actually offered a housing voucher by CHAC because of both the natural transition of families out of project-based housing units over time, and demolition of public housing in Chicago during this period (Jacob, 2004).
} 
government, or part-time work for schools or selected non-profits. ${ }^{9}$ We consider an individual to be employed in a particular quarter if she has positive earnings during that period.

Public assistance files from the Illinois Department of Human Services (IDHS) provide information on AFDC/TANF, Food Stamp and Medicaid receipt from 1989 through the end of 2005. This information contains the starting and ending dates of all social program spells, from which we create indicators for whether any assistance is received during a given quarter.

For the main analyses presented below, we limit our sample to the set of CHAC applicants who were working-age (i.e., younger than 65 years old), able-bodied (i.e., not disabled, as self-reported on the application form) and living in private-market housing when they applied to the voucher lottery. Table I presents summary statistics of the baseline characteristics for this sample for our treatment group (lottery numbers 1 to 18,110) and control group $(35,001$ to 82,607$)$. The majority of applicants in our sample are low-income AfricanAmerican women, with 1.8 children on average. We estimate average annual baseline income and rent to be $\$ 14,000$ and $\$ 8,160$, respectively (see Appendix D), suggesting that even if families have some unreported income, they must still be devoting a large share of income towards rent. These figures are consistent with previous estimates that more than one in five of all renter households in Chicago devote over half their income towards rent. ${ }^{10}$ The average fair market rent (FMR) for our sample was approximately $\$ 12,000$ per year. The average CHAC applicant would be required to contribute around $\$ 3,735$ per year towards rent under the voucher program rules, so that the average maximum subsidy is $\$ 8,265$ per year. Reeder (1985) estimates the ratio of mean benefit to mean subsidy for housing vouchers to be around .83 , so that the average equivalent variation of a housing voucher for our sample is $\$ 6,860$ per year. Because the average family that leases up with a voucher could reduce out-of-pocket spending on rent from $\$ 8,265$ to $\$ 3,735$, they can essentially take over half of the voucher subsidy as cash.

The key to estimating the effects of these housing subsidies on labor supply is that CHAC assigned applicants randomly to the program wait list. Table I provides evidence suggesting that the CHAC randomized voucher wait-list lottery was indeed random. The mean values for the

9 Kornfeld and Bloom (1999) compare treatment impact estimates using UI and self-reported survey data on earnings for participants in the National Job Training Partnership Act, and find that while earnings levels are higher in the survey than UI data, impact estimates were quite similar across the two data sources.

10 The Census Bureau's Fact Sheet for Chicago indicates there are a total of 515,047 renter households in the city, while the Chicago Rehab Network estimates that 117,000 renter households are spending more than 50 percent of their incomes on rent. (www.chicagorehab.org/takeaction/facts.htm, accessed on October 14, 2008). 
11,696 treatment applicants and 30,662 control group applicants for the baseline (i.e., prelottery) characteristics listed in Table I are virtually identical. Only two of the 26 pair-wise differences are significant at the 5 percent level, and the magnitudes of the differences are quite small. An omnibus test of the differences between the treatment and control groups that accounts for the correlation among our baseline characteristics yields a p-value of .98. ${ }^{11}$

Roughly half of those in the treatment group used a voucher. While the treatment group "compliers" differ from the "non-compliers," this does not bias our estimates below because we focus on the essentially "experimental" comparison of all treatment to all control families.

\section{EMPIRICAL STRATEGY}

Given that the voucher wait list lottery was random, a simple comparison of means between those offered vouchers and those who were not provides an unbiased estimate of the effects of being offered a voucher (the intent to treat effect, or ITT). Our application is complicated slightly by the fact that people were offered vouchers at different points in time. In this section we discuss how we estimate the ITT effect as well as the effects of using a voucher.

\section{A. The Effect of Receiving a Voucher Offer}

Our data consists of a balanced panel where the unit of observation is the householdquarter, from 1997:Q3 (the first post-lottery quarter) through 2005:Q4. For some outcome $y_{i t}$ for CHAC applicant $i$ in calendar quarter $t$, we use OLS to estimate the ITT effect from equation (1):

$$
y_{i t}=\alpha+\beta_{1}\left(\text { Postoffe } e_{i}\right)+\beta_{2}\left(\operatorname{Pr} e O f f e_{i}\right)+\mathbf{X} \Gamma+\gamma_{t}+\varepsilon_{i t}
$$

PostOff $e_{\ell l}$ equals 1 if individual $i$ has been offered a housing voucher through the CHAC 1997 lottery in any period prior to $t$, and zero otherwise. PreOffer ${ }_{i t}$ equals 1 for individuals in the treatment group in the post-lottery quarters prior to their voucher offer. We also control for calendar year-quarter effects, $\gamma_{t}$, to account for changes over time in economic conditions. Among the control group, employment rates rose through 2000 then declined, while rates of public assistance receipt fell steadily over our study period (Appendix Figure I). These patterns mirror trends in the Chicago-area unemployment rate and rental vacancy rate (Appendix Figure II). To increase statistical precision, we control for a set of individual and family baseline

$11 \mathrm{We}$ conduct an omnibus F-test of the differences between the treatment and control group by estimating a seemingly unrelated regression (SUR) where all of the characteristics listed in Table I are stacked as Y (outcome) variables and the only $\mathrm{X}$ variable is an indicator for treatment group status and a constant. We conduct this test two ways, first clustering standard errors at the household level, and then again clustering at the baseline census tract level. In either case, the p-value is far from the conventional threshold for statistical significance. 
characteristics, $\mathbf{X}$, which are described in detail in Appendix C. Standard errors are clustered by household (Bertrand et al., 2004).

In equation (1), identification of the main Intent-to-Treat (ITT) effect, given by $\beta_{1}$, comes from a within-period comparison of the average outcomes of those offered vouchers versus the control group. If there is heterogeneity in the effects of a voucher offer on labor supply across people, calendar time or duration of voucher receipt, then our ITT estimate can be interpreted as an average of the ITT effects across all post-voucher-offer person-quarter observations in our panel. The coefficient $\beta_{2}$ on the PreOffer indicator provides some evidence on whether families change their behavior in anticipation of getting a voucher. This coefficient does not serve as an additional "randomization check," since it is estimated off of postrandomization treatment-control differences (recall our panel only includes post-lottery quarters).

The main threat to the internal validity of our estimates comes from the possibility that our treatment and control groups might move out of state at differential rates, since we rely on Illinois data and families can use their vouchers to move elsewhere. However, our address data show that around 10 percent of households in both the treatment and control groups spent at least some time between 1997:Q3 and 2005:Q4 out of Illinois; the average fraction of quarters spent outside of Illinois was .042 for both treatment and control households.

\section{B. The Effects of Using a Voucher}

Under the assumption that the voucher offer does not have an impact on those who choose not to take it, ${ }^{12}$ one can use the exogenous variation in voucher offers generated by the randomized July 1997 CHAC wait-list lottery to estimate the effect of utilizing a housing voucher. We implement this in a two-stage least squares framework:

$$
\begin{aligned}
& \text { Leased }_{i t}=\alpha+\theta_{1} \text { PostOff err }+\theta_{2} \operatorname{Pr} \text { OOffe ert }+\mathbf{X} \Gamma+\gamma_{t}+\varepsilon_{i t} \\
& y_{i t}=\alpha+\pi_{1} \text { Leased }_{i t}+\mathbf{X} \Gamma+\gamma_{t}+\varepsilon_{i t},
\end{aligned}
$$

For the first-stage equation in (2), the outcome is an indicator for whether household $i$ had utilized a housing voucher provided by any source by period $t$. Under this definition a family that uses but then gives up their voucher does not become "untreated." If we were sure the only relevant behavioral mechanisms were income and substitution effects, we might define treatment more narrowly as active use of a voucher in a given quarter. But the housing literature

12 While we do not think this assumption is strictly true, we believe that it is a reasonable approximation. 
provides some reasons to believe there could be other channels through which vouchers could affect work. ${ }^{13}$ In addition, our definition of "treatment" also includes families who use vouchers obtained through other special voucher allocations, ${ }^{14}$ so we are essentially estimating what happens when we expand the overall number of vouchers in circulation.

If the effects of a voucher on behavior do not vary by time since lease-up, then our instrumental variables (IV) estimate for $\pi_{1}$ captures the local average treatment effect (LATE) on those who are induced to use a voucher by being assigned a good lottery number by CHAC (Angrist, Imbens and Rubin, 1996). If voucher effects instead vary by how long a family has been leased up, then $\pi_{1}$ captures the LATE for those who lease up for a longer period of time due to treatment group assignment, so long as we are willing to assume that control group crossovers would have been leased up for the same amount of time had they instead been assigned to the treatment group. If we instead use a more conservative assumption that all treatment group voucher users lease up for a longer period of time than if they had been assigned to the control group, our IV estimate will capture the effects of treatment on the treated (TOT). We show below that using alternative definitions of "treatment" does not change our findings, which is not surprising given that our control group crossover rates are relatively low.

As a benchmark for judging the size of our IV estimates, we present what Katz, Kling and Liebman (2001) call the control complier mean (CCM), or the average outcome for controls who would have used vouchers had they been assigned to the treatment group. The CCM is estimated by subtracting $\pi_{1}$ from the mean outcome for the treatment group compliers. ${ }^{15}$

13 For instance, if a family uses a voucher to move to a neighborhood that is closer to job opportunities and filled with more employed neighbors who can provide useful job references, and as a result gets a good job that boosts the family's income beyond the eligibility limit of the voucher program, we would not wish to count it as being "untreated" after it leaves the voucher program.

14 HUD financed the Chicago Housing Authority (CHA) to demolish a number of the city's most notorious housing projects through the Hope VI program, and some displaced families were offered housing vouchers instead. Other families on the $\mathrm{CHAC}$ application list could have received vouchers from another program because they contained a disabled member, or were at risk for having parents separated from children without a change in housing status, or were Latino and so received vouchers as a result of litigation by Latinos United against the CHA.

15 This CCM calculation assumes a TOT interpretation of the IV estimate, in which all of the treatment group families who use a voucher are "treated." If the IV estimate is instead given a LATE interpretation as the average effect of voucher use on those families who lease up if assigned to the treatment group not but if they are assigned to the control group, then the CCM will not be quite the right benchmark for the IV, but it should be close given that control group cross-over rates are relatively low. 


\section{Changes in Treatment Effects over Time}

We are also interested in how voucher effects might change over time, both for policy purposes and to learn more about underlying behavioral mechanisms. To do so, we calculate ITT effects for each period after the voucher offer, using the following equation:

$$
y_{i t}=\alpha+\sum_{k} D_{i t}^{k} \delta_{k}+\mathbf{X} \Gamma+\gamma_{t}+\varepsilon_{i t}
$$

where the binary variables $D_{i t}^{k}$ equal 1 if, in period $t$, individual $i$ is $k$ periods from when they were offered a voucher (where k can take on positive and negative values). The coefficients $\delta_{k}$ capture the effect of a voucher offer over time relative to when the voucher was offered. ITT estimates by time relative to the voucher offer reflect the net (reduced form) effect of a variety of factors. The ITT effect could be changing over time because the behavioral response to leasing up with a voucher varies, or because the fraction of treatment or control group families that have leased up with a voucher changes over time. ${ }^{16}$ Moreover, changes in the ITT over time may reflect, in part, the fact that the voucher impact varies over calendar time because, for example, of changes in the economy. We explore some of these sources of heterogeneity below.

In principle, we might also like to estimate the effects of actually being leased up for a given period of time. However we cannot identify this parameter without imposing additional structure on the data, ${ }^{17}$ and so instead focus on the simpler ITT-by-time estimates instead.

16 If the treatment effects are heterogeneous, then changes in the composition of compliers (i.e., those treatment and control families who are utilizing a housing voucher) may also contribute to changes in the ITT effects over time. 17 For example, Gubits et al. (2006, Appendix B) present a method for estimated the effects of being leased up for a given duration that uses a recursive approach, in which they first calculate the effects of being leased up for one period (which they can identify with their data) and then use that estimate to back out the effects of being leased up for two periods, then use both of those estimates to back out the effects of being leased up for three periods and so on. But their estimation approach assumes that the effect of being leased up for one period in the first period since random assignment is the same as the effect of being leased up for one period in the second period since random assignment. This assumption may be violated if the people who lease up with some delay have a different behavioral response to vouchers from those who lease up right away after the voucher offer. The assumption may also be violated if the effects of using a voucher depend on the point in calendar time when the voucher is used, as may be the case for example if housing market conditions influence housing search outcomes. The staggered rollout of housing vouchers in our case allows us to identify the impact of calendar time on voucher utilization, but still does not allow us to identify the impact of calendar time $\mathrm{x}$ voucher use or time of usage (usage intensity) effects without further assumptions. Angrist and Imbens (1995) provide a framework in which one can estimate average causal effects in models with variable treatment intensity, which would be an alternate approach for understanding how voucher effects differ by time since offer. Thanks to Jeffrey Kling for very helpful discussions on this issue. 


\section{RESULTS}

We show that being offered a voucher through the CHAC wait list increases the chances of using a voucher, and that voucher use reduces work and earnings, increases social program participation, but has little impact on neighborhood environments or residential stability.

\section{A. Effects of the CHAC Lottery on Voucher Utilization}

The vouchers allocated by CHAC through the 1997 wait list lottery represent the largest, but not the only, voucher allocation in Chicago during our study period. By the end of our study period in 2005, nearly 8 percent of control households had used a voucher obtained from some other allocation (Appendix Figure III). Nonetheless, receiving a voucher offer through the 1997 wait list lottery substantially increases the chances of utilizing a voucher, as shown in Table II. Column 1 shows the coefficient on the PostOffer indicator from estimating equation (2). The control mean indicates that, in the average quarter, 5.3 percent of controls used a voucher. Assignment of a good wait list number by CHAC increased voucher lease-up rates by roughly 40 percentage points (the F-test statistic is over 7,500). To more clearly illustrate the total fraction of households who ever utilized a housing voucher, in column 2 we regress an indicator of ever utilizing a housing voucher on an indicator for ever receiving a voucher offer through the 1997 wait list (i.e., at any point between 1997 and 2003), conditional on a set of baseline covariates. The unit of observation now is the household, not the household-quarter. A total of 7.6 percent of control families obtained a voucher at some point. Households that received a voucher offer were 42.6 percentage points more likely than controls to use a voucher over our sample period. Two-thirds of treatment group compliers use their vouchers within the first quarter of the voucher offer, and over 90 percent lease up within a year of the offer.

As noted above, there are a variety of reasons why families may not utilize a housing voucher when offered one. These take-up rates are in the ballpark of those from other studies (Rubinowitz and Rosenbaum, 2000, Olsen, 2003, Kling, Liebman and Katz, 2007). Columns 3-7 explore the heterogeneity of voucher utilization by regressing an indicator for whether a household ever uses a voucher over our sample period against a series of baseline covariates, using a dataset with one observation for each of the 11,696 treatment households in our sample. Column 3 presents the results of a series of bivariate regressions in which each baseline characteristic is entered separately, while columns 4-7 show models that condition on multiple covariates simultaneously. Households living in more disadvantaged baseline neighborhoods or 
receiving TANF at baseline are more likely to lease up if offered a voucher. Older, male or employed applicants are less likely to lease up. We also see that cohorts offered vouchers in 2000 and 2001 had lease-up rates several percentage points lower than the earlier and later offer cohorts. We later examine the degree to which trends in labor or housing market conditions explain these cohort differences.

\section{B. Effects of a Voucher Offer on Employment, Earnings and Social Program Participation}

Table III presents the main results for our sample of working-age, able-bodied applicants living in private housing at baseline. The table shows both the estimated post-offer ITT and IV estimates on a variety of outcomes. We defer the discussion of pre-offer (i.e., anticipation) effects to a later section where we discuss how the impacts vary by time relative to offer.

Voucher use reduces quarterly employment rates by 3.6 percentage points ( 6 percent of the CCM). While we cannot directly measure hours worked, voucher receipt reduces the likelihood that someone earns what would be the equivalent of working full time at $\$ 6$ an hour, or $\$ 2,415$ a quarter, by 4.5 percentage points, or 10 percent. ${ }^{18}$ Voucher use reduces quarterly earnings by $\$ 328$, or 11 percent of the CCM. Unless the decline in work for the treatment group is concentrated among high earners, or else treatment group members shift to less well-paid jobs, then our estimated IV effect of $-\$ 228$ on earnings conditional on working implies a reduction in hours worked - that is, an effect on both the intensive and extensive margins of labor supply.

Table III also shows that voucher use increases participation rates in social programs (TANF, Medicaid or Food Stamps) by nearly 7 percentage points, equal to around 12 percent of the CCM. The effect on TANF participation is smaller in absolute terms (about 2 percentage points) but larger as a share of the CCM, given that only 11 percent of the would-be compliers in the control group are on TANF during our study period. ${ }^{19}$ Most of the increase in social program receipt seems to be concentrated among the Medicaid and Food Stamp programs.

One limitation of the focus on household heads in Table III is that it will not pick up any impacts of voucher assistance on other household members. The fact that housing program rules exclude earnings of children under 18 in calculating income means a household could reduce its required rent payment by substituting labor supply by teenagers in the home for labor supply by

18 Quarterly earnings would equal \$2,415 for someone who was working 35 hours per week, 11.5 weeks, at \$6 an hour. The results in proportional terms are virtually identical if we assumed a wage of $\$ 8$.

19 Note that TANF receipt rates decline substantially over our study period among our control group, from 41 percent at baseline (Table I), to 15 percent averaged over all post-lottery quarters (Table III), which mirrors the large declines in welfare caseloads that have been observed throughout the U.S. 
adults. But when we replicate our analyses using data on work, earnings, or social program participation by everyone in the home, we get similar results to Table III (see Appendix Table I).

Table IV presents estimates for a variety of additional subgroups. To simplify the presentation we focus on just two outcomes: quarterly labor force participation, shown in the first four columns, and quarterly participation rates in any social program (TANF, Medicaid or Food Stamps). The first row replicates the results for our main analytic sample. The second and third rows show that the behavioral responses among those CHAC voucher applicants who were elderly (3 percent of all applicants) or disabled (26 percent) are, not surprisingly, smaller in relation to either the standard errors or the control complier means. Interestingly, voucher use increases social program participation among disabled voucher applicants, even though we find no detectable impact on employment rates. It is possible that interaction with voucher program administrators makes disabled participants aware of their eligibility for other social services, although this hypothesis is not directly testable with our data. Estimated voucher effects on labor force participation rates are smaller among male than female household heads, but the men in our sample seem to be unusual, since they have lower average employment rates than the women.

While there are no significant differences in voucher effects by baseline employment status, there are large and statistically significant differences in the effects by baseline social program participation. Voucher use reduces employment by 6.1 percentage points ( 9 percent) among those who were not receiving benefits at baseline, and only by 2.5 percentage points ( 4 percent) among those receiving benefits. A similar pattern is apparent if one focuses just on TANF receipt. These differences in voucher effects are consistent with the idea that changes in marginal tax rates caused by vouchers is a key mechanism behind these labor supply impacts, since participation in other social programs mitigates the effect of vouchers on marginal tax rates (see Appendix A). Of course, it is also possible that more disadvantaged families simply have different preferences about labor supply and levels of labor market attachment, and so are less responsive to changes in work incentives. ${ }^{20}$ The last three rows show the voucher effects are larger in absolute value for those offered vouchers in 1997-98 as compared to later periods.

20 Employment impacts seem to be somewhat smaller among families with relatively more children, but this is not true when we look at social program participation as the outcome. When we split the sample by baseline neighborhood characteristics, we find families living in more affluent census tracts experience a smaller labor supply reduction from using a voucher. But, as above, this pattern does not show up for social program participation. 
Our results for the effects of using a voucher are qualitatively similar under a variety of alternative specifications (e.g., defining voucher use as only using a voucher from the 1997 waiting list, defining voucher use as "active" use only, etc.), as shown in Appendix Table II. This is not surprising given that the share of treatment and control group families who use vouchers obtained through other special voucher allocations besides the CHAC July 1997 voucher wait-list lottery are relatively low. ${ }^{21}$

\section{Effects of a Voucher Offer by Time Since Offer}

Examining how voucher impacts vary with time since offer can inform our understanding of the mechanisms underlying the impacts. For example, if the labor supply effects were driven by the disruption that vouchers impose on families (e.g., the time required to find a suitable apartment, actually move, and then adjust to the transition), then we would expect any negative labor supply effects to dissipate over time. On the other hand, we might expect the impacts from income and substitution effects to increase over time, if it takes families some time to adjust their employment situations to the new incentives that they face.

To examine the time path of voucher effects, we estimate equation (4) using a series of indicators for the year relative to voucher offer. Figure II shows the ITT estimates by time since offer, along with the 95 percent confidence band, for employment, earnings and public assistance receipt. For all of the outcomes, we see that the impacts get larger in absolute value with time since the voucher offer, suggesting our results are not simply due to the disruption of moving. If we limit our sample to the set of families who are on TANF at baseline, we find a similar pattern (see Appendix Figure IV). In that sense our findings appear to be at odds with the Welfare-toWork (WtW) voucher experiment, which found significant reductions in work the first year after random assignment, but not in years two and three (Gubits et al., 2006). However, as noted earlier, the WtW experimental sample was limited to just those determined by the local housing authority to need a voucher to maintain employment, which may be a quite different group from the average baseline TANF recipient who applied for a housing voucher in Chicago.

\footnotetext{
21 Specifically, the Appendix Table II shows that our results are similar when we: add to our control group those families with lottery numbers from 18,103 to 35,000 , who expected to receive CHAC vouchers at some point but had not been offered vouchers by the end of 2003; redefine "treatment" to be receipt of vouchers only through the 1997 CHAC lottery allocation, rather than from any program, so that we are now estimating the effects of treatment on the treated (TOT) for the CHAC voucher treatment; define "treatment" as use of a voucher in a given quarter, rather than having used a voucher at any time in the past (consistent with the idea that treatment group compliers use their vouchers for some time); or define "treatment" as use of a 1997 CHAC lottery voucher in a given quarter (combination of latter two specifications).
} 
These results also provide evidence of some small anticipation effects on employment. In Figure IIa, for example, we see that treatment families seem to be slightly more likely to work (relative to control families) in the years after the wait list lottery but prior to their actual voucher offer. In results not shown here, the coefficient on the single PreOffer indicator in equation (1) is .006 with a standard error of .003, suggesting the voucher offer increases employment by roughly six-tenths of a percentage point, or one percent of the control mean. Note that this statistically significant coefficient is not an indication of model misspecification or improper randomization, since it comes from comparing post-lottery person-quarter observations for treatment families while they are waiting for a voucher to the outcomes of control families in the same calendar quarter. This reflects a real behavioral response, and is consistent with families wishing to substitute labor supply from periods when real wages are relatively low to those where real wages are relatively high. There is less clear evidence of any anticipation effects on social program participation (Figure IIc).

\section{Effects of a Voucher Offer on Residential Stability and Neighborhood Environment}

The results thus far indicate that the in-kind subsidy provided by housing vouchers reduces labor supply to a modest degree. This effect is consistent across a variety of subgroups, is robust to several alternative specifications, and does not appear to be due to a short-term disruption effect. In Table $\mathrm{V}$, we explore some of the potential mechanisms underlying these impacts using the 10 percent random sub-sample for whom we collected address histories. ${ }^{22}$

We first consider impacts on residential stability. While it is likely that a housing voucher will induce higher mobility in the short-run as families lease new apartments, some observers have hypothesized that rent subsidies will actually decrease residential mobility in the longer run, which may improve labor market outcomes. In row 1 of Table $\mathrm{V}$, we see that the use of a housing voucher did not have any significant impact on the number of different addresses at which the household resided. Figure III, which shows the ITT effects on residential mobility by time relative to offer, provides greater insight. It appears that voucher offers change the timing of moves: treatment families who are expecting to receive a voucher are less likely to move than controls until they are offered a voucher, and then become more likely than controls to move.

22 In results not shown, we replicate the basic findings shown above on labor supply and social program participation using data just from this 10 percent sub-sample, which gives us more confidence that we can generalize the address history results found here to our full sample. 
Presumably treatment group families are postponing moves so that they can move into better housing units or neighborhoods with a voucher.

The remainder of the results in Table $\mathrm{V}$ suggest that vouchers have little, if any, impact on a household's neighborhood environment, another housing-specific mechanism that has been hypothesized to promote work. Each row in Table V presents results for a separate neighborhood characteristic, including tract poverty rate, time spent in "low poverty" tracts (poverty rate below 20 percent), tract share black, two measures of neighborhood social functioning - collective efficacy, and social capital, taken from the community survey of the Project on Human Development in Chicago Neighborhoods ${ }^{23}$ - and property and violent crime rates from the Chicago Police Department measured at the beat level. For each neighborhood measure, the estimated voucher effects are small relative to both the standard errors and CCMs. We find little evidence that the neighborhood environments of voucher users are improving relative to controls with time since the voucher offer (Figure III).

\section{E. Non-Experimental Estimates of Voucher Impacts}

As a way to understand how one might reconcile our results with the previous nonexperimental literature, in Table VI we re-estimate the "effects" of vouchers using only the nonexperimental variation in voucher usage within our dataset. ${ }^{24}$ We do this in the top panel of Table VI by restricting our analytic sample just to our control group (lottery numbers above $35,000)$, which could have obtained vouchers through several different "special allocations" offered during our analysis period. These programs operated independently of the main CHAC voucher wait list and provided small numbers of vouchers to other families over our study period. In the bottom panel of Table VI, we use data just from the treatment group, so that all of the variation in voucher usage comes from the willingness or ability of families who are offered vouchers through the main CHAC 1997 voucher wait list lottery to actually lease up with one of these vouchers.

23 These variables come from the 1995 PHDCN community survey, which surveys a random sample of residents within each of the city's "neighborhood clusters," which the PHDCN formed on the basis of grouping together census tracts. We focus on collective efficacy (willingness of neighbors to work together to promote shared norms) and social disorder given claims in previous research for their importance in explaining a variety of behavioral outcomes, including crime (Sampson, Raudenbush and Earls, 1997). Unfortunately the data from the 2002 PHDCN community survey are not yet publicly available..

24 In a separate ongoing project joint with Jeff Smith, the authors are examining the correspondence between a range of experimental and non-experimental estimates of the impact of housing vouchers on a variety of outcomes for children and adults in public as well as private housing at baseline. 
The third column of Table VI replicates our "experimental" IV estimates as a benchmark for the subsequent non-experimental estimates. In column (4), we present the results of a simple bivariate OLS regression of our different dependent variables of interest against voucher use. We see that these bivariate relationships are almost always larger in absolute value than our experimental IV estimates. Column (5) shows that conditioning on the fairly rich set of baseline covariates available to us in the CHAC dataset, including baseline labor supply and social program participation as well as characteristics that are often unmeasured in population surveys (e.g., disability status) substantially reduces the degree to which the non-experimental estimates overstate the experimental IV effect for many, but not all, our outcomes of interest. This pattern is generally similar whether we use the control group or the treatment group to generate our nonexperimental estimates. This suggests that previous non-experimental cross-sectional studies might overstate the true causal effects of vouchers on labor supply or self sufficiency if the covariate information available is limited.

Column (6) takes advantage of the longitudinal structure of our data and controls for individual fixed effects, so we are identifying off of within-person over-time changes in voucher status. We are struck by the fact that the correspondence between these non-experimental fixedeffects estimates and the experimental IV estimates varies so much across our different dependent variables, regardless of whether we use the control group or the treatment group to generate our non-experimental results. For example, the fixed-effects estimate understates the negative effects of voucher use on employment (basically zero, compared to an experimental IV effect of -3.6 percentage points), suggesting that people who self-select into using a voucher are predisposed towards working around the time they use their vouchers. We can see this even more sharply when we look at TANF receipt as the dependent variable of interest, where the fixed-effects estimates suggest people receiving vouchers are less likely to use TANF (around -8 percentage points), while the experimental IV estimate suggests vouchers increase TANF receipt by around 1.6 percentage points. On the other hand, the fixed-effects estimate for voucher effects on earnings conditional on working is almost exactly equal to the experimental IV estimate. In our sample, it appears that people who are relatively motivated to work and stay off 
welfare are the ones most likely to select into using a voucher, but that there is little selection going on with respect to earnings potential (i.e., market wages). ${ }^{25}$

In summary, the pattern of non-experimental estimates shown in Table VI do not provide a clear story about whether or how voucher usage affects self sufficiency, consistent with the conclusions of previous reviews of the existing non-experimental literature. In contrast, our experimental estimates clearly indicate that vouchers lead to a modest reduction in labor supply.

\section{F. The Relationship between Voucher Effects and the Economy}

In Table IV, we presented some evidence indicating that the voucher effects on labor supply may be largest for those CHAC applicants who were offered vouchers relatively earlier during the post-lottery period. In Figure II, we saw that voucher effects increased with time since offer. While this treatment heterogeneity could be caused by a variety of factors, Herbst (2008) argues that the impact of social policy may vary as a function of the macroeconomy and, as noted above, there were large changes in the local economy over our sample period.

To explore this issue further, we estimate a model similar to equation (4) but that includes a full set of interactions between the quarter-relative-to-offer and the calendar-quarter in which the household was offered a voucher. In total, this model yields 405 separate post-offer ITT effects measured at the level of offer quarter $\times$ calendar quarter. We then estimate a series of models with these ITT's as the dependent variable. As predictors, we include measures of the unemployment rate both at the time the household was offered a housing voucher as well as the time in which the outcome was measured, the difference between the treatment and control groups in voucher utilization rates, and the number of years since families in the treatment group had been offered vouchers in each calendar-quarter. ${ }^{26}$ To improve efficiency, we estimate these via GLS using the covariance matrix from the first-step regression as a weighting matrix in the second-step regression. Because we estimate clustered standard errors at the household level in the first-step, and all households are by construction nested in a particular treatment offer cohort (or in the control group), the resulting covariance matrix of ITT effects captures the serial

\footnotetext{
25 It is true that because the experimental IV and non-experimental fixed-effects model generate different estimates for the effects of vouchers on labor force participation rates, the experimental versus non-experimental estimates for voucher effects on earnings conditional on work will be comparing slightly different sets of people. But because the labor force participation effects estimated in our IV are relatively small, we would need mean earnings for a small subset of people to be very far from the average to change the basic story that there is not much selection into voucher use based on earnings potential.

26 Note that the rental market vacancy rate and the unemployment rate are highly correlated in Chicago during this period so we cannot distinguish effects of housing versus labor market conditions.
} 
correlation within offer cohorts over time that one would expect, with larger standard errors on the offer cohort level predictors in our second-step model. ${ }^{27}$ The top and bottom panels of Table VII consider employment and social program participation rates, respectively. It is important to note that this analysis does not exploit any experimental variation, and thus should be interpreted as a simple association. It is possible that other unobserved factors correlated with the local economic conditions could be driving the results presented here.

While the estimates are not particularly precise, several interesting patterns emerge. In general, it appears that a weak economy in the current period exacerbates the work disincentive effect associated with using a housing voucher. That is, at times when the unemployment rate is higher, the treatment-control difference in public assistance usage and employment may also be larger in absolute value. For example, the coefficient of .002 in the bottom panel suggests that a one-percentage point increase in the current unemployment rate is associated with a .002 increase in the ITT effect on public assistance receipt. One possible explanation is that interaction with CHAC may have increased families' awareness and familiarity with other social service options, so that in bad economic times they were better positioned to utilize services.

In contrast, it appears that weak economic conditions at the time of voucher offer might mitigate the work disincentive effects associated with a voucher offer. For example, the coefficient on the offer year unemployment rate of .006 in the top panel suggests a 1 percentage point increase in the unemployment rate would lead to a .006 increase in the ITT effect (relative to an average ITT of -.017). It is possible that a weak economy reduces the ability of voucher recipients to change jobs or adjust hours at their current job. In the same way that the economic conditions that exist when one enters the labor market can influence earnings for many years (Oreopoulous, von Wachter and Heisz, 2008), the initial conditions at the time of voucher offer may exert an enduring influence on the labor supply decisions of recipients.

We had also hypothesized that differences in labor market or housing conditions at the time families were offered vouchers could help explain differences in voucher effects across voucher offer cohorts (Table IV). In results not shown, however, we show that proxies for the macroeconomic conditions cannot explain much of the difference across voucher offer cohorts.

27 The bottom row of Table VII also provides a test of the overidentifying restrictions in this model. The fact that the p-value for every specification is greater than .05 provides some evidence that the model is correctly specified. 


\section{DISCUSSION}

The random assignment of voucher applicants in Chicago during the late 1990s provides

us with a unique opportunity to identify the causal effects of a large, understudied social program (housing assistance) on labor supply and self sufficiency. Existing theoretical work yields ambiguous predictions about the sign, much less the magnitude, of any relationship. In contrast to the well-known Moving to Opportunity experiment, which offered vouchers to families in public housing at baseline, we focus in our study on people who were living in private-market housing at the time they applied for a voucher, the group that accounts for the vast majority of all voucher applicants in Chicago and other large cities. The treatment we examine, therefore, consists of both an increase in income and marginal tax rates, but not necessarily a change in neighborhood environment. Our estimates capture the effect of expanding the set of people receiving housing assistance by issuing more vouchers, and may shed light on the labor supply response of in-kind means-tested transfers more generally.

Our estimates allow us to soundly reject the hypothesis that housing voucher receipt is work enhancing, or even work neutral. We estimate that voucher receipt reduces quarterly employment rates by around 3.6 percentage points (about 6 percent of the control complier mean), reduces earnings by around $\$ 328$ per quarter (11 percent of the CCM), increases TANF receipt rates by around 1.6 percentage points (15 percent of the CCM), and increases receipt of any social program benefits by 6.7 percentage points ( 12 percent of the CCM). We also find that the treatment group increases labor supply slightly during the periods before they are offered a voucher, consistent with the prediction of the life cycle labor supply model that people may shift work effort towards those periods with relatively higher wage rates (although this effect is quite small - around 0.6 percentage points, or about one percent of the control mean).

We find little evidence in support of two of the main work-enhancing mechanisms that have been hypothesized for housing vouchers, namely significant improvements in neighborhoods or residential stability. Voucher receipt does seem to change the timing of moves, as families on the voucher program wait list seem to defer moving until they are offered a voucher, but does not have much effect on the total number of moves. Moreover, vouchers appear to have no significant impact on a family's neighborhood environment.

Since we find relatively little evidence that housing-specific mechanisms appear to be very important for labor supply, our findings may also be relevant for understanding labor supply 
responses to other social programs as well. Since voucher receipt generates income and substitution effects that work in the same direction to reduce labor supply, our reduced form estimates for the effects of voucher usage on labor supply enables us to generate bounds for both effects. Since most CHAC voucher applicants have baseline incomes far below the phase-out range, and so should remain income-eligible for quite some time, our estimates presumably capture how people respond to perceived permanent changes in their budget constraints.

Our reduced-form estimates imply that the wage elasticity with respect to working full time ( 35 hours or more per week) is not more than +.3 to +.4 , which is far smaller than the estimate of +1.82 from Keane and Moffitt (1998). ${ }^{28}$ For total hours worked, our estimates suggest that the income and substitution elasticities for hours worked by our sample are not any larger than around -.20 and +.33 , respectively. ${ }^{29}$ Our upper bound of .33 for the substitution effect is far smaller than that from Kimball and Shapiro (2008), who use survey data about hypothetical labor supply responses to estimate a utility-constant elasticity of hours with respect to a permanent change in the wage rate of around .57 for single females. On the other hand, our upper bounds fit comfortably alongside the income and substitution elasticities that have been estimated for single female household heads from the Negative Income Tax experiments, equal to -.16 and +.13 , respectively (Robins, 1985 , p. 580).

An alternative way to think about the magnitude of our estimates is to compare the deadweight losses associated with vouchers to the resources transferred to poor families. As noted above, the average family in our sample has baseline earnings of around $\$ 14,000$ per year, while the average value of a housing voucher subsidy for these families is about \$8,265 per year. We can approximate the size of the deadweight loss induced by labor supply reductions using

28 As noted above, the equivalent variation of a voucher to our sample of $\$ 6,860$ is equal to around 49 percent of the mean baseline income of $\$ 14,000$. For the wage elasticity, Hassett and Moore (2005) suggest the average marginal tax rate is around zero for unmarried women with children with incomes around the baseline mean in our sample, so that an increase in the marginal tax rate of 30 percentage points reduces the after-tax wage by 30 percent. Unfortunately we do not have data on hours worked in our UI data. But if we assume the average wage for CHAC applicants was $\$ 6$ an hour for both the treatment and control group, then our results in Table III suggest that a 30 percent reduction in the after-tax wage from using a voucher reduces full-time work by 10 percent (TOT effect of -.045 , and a CCM of .47), so that the elasticity cannot be larger than $(.1 / .3)=.33$. If we assume instead an average wage of $\$ 8$ per hour, then Table III implies voucher use reduces full-time work by 11 percent and the elasticity is no more than $(.11 / .3)=.37$.

29 Without data on hours of work, we assume that a 10 percent reduction in earnings implies a 10 percent reduction in hours (which in turn assumes treatment assignment has no effect on wages). The equivalent variation of a voucher is equal to 49 percent of baseline income, so that the income elasticity of hours is no larger than $(-.1 / .49)=$ -.20 . If vouchers reduce the after tax wage by 30 percent (see previous footnote), then the elasticity of the substitution effect of hours worked is no larger than $(-.1 / .3)=.33$. 
Arthur Harberger's welfare triangle (one-half price $\times$ change in quantity), which our estimates suggest is around $\$ 660 .{ }^{30}$ Whether this is large or small in relation to the size of resource transfer to low-income families is a normative policy judgment.

We could also consider the magnitude of our estimated effects within the context of what Arthur Okun (1975) called the "leaky bucket" that society uses to transfer resources to the poor. How big is the leak? Setting aside for the moment program administration costs and deadweight losses associated with raising tax revenues, the average government cost of a housing voucher for families in our study is around $\$ 8,400$ per year, and the equivalent variation is around $\$ 6,860$. Voucher use reduces annual earnings by around $\$ 1,312$ among program participants, or around 19 percent of the value of the subsidy to voucher recipients. Using the standard for judging the size of work disincentive effects suggested by Blank (1997), eliminating the housing voucher program altogether would substantially increase the degree of material deprivation among poor families despite the fact that they would work and earn more.

In any case, our results clearly indicate that housing vouchers reduce labor supply to some degree. This finding is relevant to a variety of policy decisions about the optimal design of housing programs. A recent HUD white paper on the housing voucher program notes that when given discretion, local housing agencies seem eager to experiment with different methods of relating tenant incomes to their rent payments, including flat rent systems, stepped rents, or expanding the range of income exclusions and deductions used to calculate adjusted income (HUD, 2004). Olsen $(2003,2008)$ has proposed to make housing an entitlement and provide a relatively smaller housing subsidy to all eligible families, which could reduce the implicit tax rates associated with housing assistance and thus mitigate any work disincentive effects. Evidence on the sign and magnitude of labor supply responses to the existing housing voucher program is important for assessing these alternatives to current policies.

Our findings are also relevant to debates that go back at least to the 1960s about whether to provide assistance to families through a mix of cash transfer and in-kind benefit programs, or instead through a single negative income tax program (see, for example, Friedman, 1962). There are several arguments in favor of in-kind transfers such as housing assistances, including the

30 If the average CHAC applicant earns $\$ 6$ an hour, our estimates for earnings impacts of $\$ 328$ per quarter imply 55 fewer hours per quarter, or around 220 fewer hours of work per year. The deadweight loss from reductions in labor supply then would equal $\$ 660$. The deadweight loss is about the same if we assume an average wage of $\$ 8$ per hour for our sample. 
contention that better housing has positive externalities associated with greater human capital accumulation, and a normative argument for providing a base level of assistance to individuals that is not conditioned on work. Our estimates suggest that one downside of housing programs is that it leads to a reduction in work effort, in contrast to the Earned Income Tax Credit (EITC), which has been shown to increase labor force participation rates. In short, complicated tradeoffs arise in the decision about whether to use in-kind rather than cash subsidies to address housing problems. Our study provides new evidence that is relevant to assessing these tradeoffs, and deciding how to best allocate the $\$ 25$ billion per year currently devoted to helping poor families meet their housing needs.

\section{REFERENCES}

Angrist, Joshua D. and Guido W. Imbens (1995). "Two-Stage Least Squares Estimation of Average Causal Effects in Models with Variable Treatment Intensity." Journal of the American Statistical Association, 90:431-442.

Angrist, Joshua A., Guido W. Imbens, and Donald B. Rubin (1996) "Identification of Causal

Effects Using Instrumental Variables," Journal of the American Statistical Association, 91: 444472

Bertrand, Marianne, Esther Duflo, and Sendhil Mullainathan (2004) "How Much Should We Trust Differences-In-Differences?" Quarterly Journal of Economics. 119(1): 249-276.

Blank, Rebecca M. (1997) It Takes A Nation: A New Agenda for Fighting Poverty. Princeton, NJ: Princeton University Press.

Carlson, Deven, Robert Haveman, Thomas Kaplan, and Barbara Wolfe (2008) "Long-Term

Effects of Public Llow-Income Housing Vouchers on Work, Earnings and Neighborhood Quality." University of Wisconsin-Madison, Institute for Research on Poverty Discussion Paper 1338-08.

Friedman, Milton (1962) Capitalism and Freedom. Chicago: University of Chicago Press. Gubits, Daniel B., Larry L. Orr, Gregory B. Mills, Michelle L. Wood, Bulbul Kaul, David A. Long, and Judith D. Feins (2006) The Impact of Housing Choice Vouchers on Employment, Earnings and Mean-Tested Benefits. Cambridge, MA: Abt Associates draft report.

Hassett, Kevin A., and Anne B. Moore (2005) "How Do Tax Policies Affect Low Income Workers?” University of Michigan National Poverty Center, Policy Brief \#5. 
Herbst, Chris M. (2008). "Do Social Policy Reforms Have Different Impacts on Employment and Welfare Use as Economic Conditions Change?" Journal of Policy Analysis and Management. 27(4): 867-894.

Hoynes, Hiliary W. and Diane Schanzenbach (2007) “Consumption Responses to In-Kind Transfers: Evidence from the Introduction of the Food Stamps Program." National Bureau of Economic Research, Working Paper, 13025.

Jacob, Brian A. (2004) "Public Housing, Housing Vouchers, and Student Achievement:

Evidence From Public Housing Demolitions in Chicago." American Economic Review. 94(1): 233-258.

Kain, John F. (1968) “Housing Segregation, Negro Employment and Metropolitan

Decentralization." Quarterly Journal of Economics. 82(2): 175-197.

Katz, Lawrence F., Jeffrey R. Kling, and Jeffrey B. Liebman (2001) "Moving to Opportunity in Boston: Early Results of a Randomized Mobility Experiment." Quarterly Journal of Economics. 116(2): 607-654.

Keane, Michael and Robert Moffitt (1998) “A Structural Model of Multiple Welfare Program Participation and Labor Supply.” International Economic Review. 39(3): 553-589.

Kimball, Miles S. and Matthew D. Shapiro (2008) "Labor supply: Are the Income and Substitution Effects Both Large or Both Small?” National Bureau of Economic Research, Working Paper, 14208.

Kling, Jeffrey R., Jeffrey B. Liebman, and Lawrence F. Katz (2007) "Experimental Analysis of Neighborhood Effects." Econometrica, 75(1): 83-119.

Kornfeld, Robert and Howard S. Bloom (1999) "Measuring Program Impacts on Earnings and Employment: Do Unemployment Insurance Wage Reports from Employers Agree with Surveys of Individuals?” Journal of Labor Economics. 17(1): 168-197.

Leonesio, Michael V. (1988) “In-Kind Transfers and Work Incentives.” Journal of Labor Economics. 6(4): 515-529.

MaCurdy, Thomas (1981) "An Empirical Model of Labor Supply in a Life-Cycle Setting.” Journal of Political Economy. 89(6): 1059-85.

Moffitt, Robert A. (2002) “Welfare Programs and Labor Supply." In Handbook of Public Economics. Alan J. Auerbach and Martin Feldstein, Editors. Elsevier. Pp. 2393-2430. 
Murray, Michael (1980) “A Reinterpretation of the Traditional Income-Leisure Model, With Application to In-Kind Subsidy Programs." Journal of Public Economics. 14: 69-81.

Newman, Sandra, C. Scott Holupka, and Joseph Harkness (forthcoming) "The Long-Term

Effects of Housing Assistance on Work and Welfare.” Journal of Policy Analysis and

Management.

Okun, Arthur M. (1975) Equality and Efficiency, the Big Tradeoff. Washington, DC: Brookings Institution Press.

Olsen, Edgar O. (2003) "Housing Programs for Low-Income Households." In Means-Tested Transfer Programs in the United States. Edited by Robert A. Moffitt. Chicago: University of Chicago Press. pp. 365-442.

Olsen, Edgar O. (2008) "Getting More From the Budget for Low-Income Housing Assistance." Brookings Institution Hamilton Project Discussion Paper.

Olsen, Edgar O., Catherine A. Tyler, Jonathan W. King, and Paul E. Carrillo (2005) "The Effects of Different Types of Housing Assistance on Earnings and Employment." Cityscape. 8(2): 163187.

Oreopoulous, Phil, Till von Wachter, and Andrew Heisz (2006). "The Short- and Long-Term Career Effects of Graduating in a Recession: Hysteresis and Heterogeneity in the Market for College Graduates.” National Bureau of Economic Research, Working Paper, 12159.

Reeder, William J. (1985) "The Benefits and Costs of the Section 8 Existing Housing Program." Journal of Public Economics. 26: 349-377.

Robins, Philip K. (1985) “A Comparison of the Labor Supply Findings From the Four Negative Income Tax Experiments." Journal of Human Resources. 20(4): 567-582.

Rubinowitz, Leonard S. and James E. Rosenbaum (2000) Crossing the Class and Color Lines:

From Public Housing to White Suburbia. Chicago: University of Chicago Press.

Sampson, Robert J., Stephen Raudenbush, and Felton Earls (1997) "Neighborhoods and Violent

Crime: A Multilevel Study of Collective Efficacy." Science. 277: 918-924.

Schone, Barbara S. (1992) "Do Means Tested Transfers Reduce Labor Supply?" Economics Letters. 40: 353-358.

Shroder, Mark (2002) "Does Housing Assistance Perversely Affect Self-Sufficiency? A Review Essay." Journal of Housing Economics. 11(4): 381-417. 
Susin, Scott (2005) "Longitudinal Outcomes of Subsidized Housing Recipients in Matched Survey and Administrative Data." Cityscape. 8(2): 189-218.

U.S. Department of Housing and Urban Development (2004) The Flexible Voucher Program:

Why a New Approach to Housing Subsidy is Needed. Washington, DC: HUD.

http://www.hud.gov/offices/pih/programs/hcv/fvp/wponfvp.pdf

Yelowitz, Aaron S. (2001) "Public Housing and Labor Supply." Working Paper, Department of Economics, University of Kentucky. 
HHH male

HHH black

HHH Hispanic

HHH white

HHH other

Has spouse

Number of adults in $\mathrm{HH}$

Number of kids $0-18$ in $\mathrm{HH}$

Age of $\mathrm{HHH}$

Indicated interest in the certificate program as well as the voucher program

Reported receiving Supplemental Security Income (SSI) benefits

Time (in days) of application since applications opened

HHH receiving TANF 1997q2

HHH wage (2007\$) 1997q2

HHH employed 1997q2

HHH receiving TANF, Med, or FS 1997q2

HHH number of prior violent crime arrests

$\mathrm{HHH}$ number of prior property crime arrests

$\mathrm{HHH}$ number of prior drug crime arrests

HHH number of prior other crime arrests

Percent black in census tract

Poverty rate in census tract

Census tract property crime (crimes per 1,000 residents)

Census tract violent crime (crimes per 1,000 residents)

Monthy rent, 2007\$

Monthly fair market rent, 2007\$

Number of Households

F-statistic (clustering at the $\mathrm{HH}$ level)

p-value

\begin{tabular}{|c|c|c|c|}
\hline \multirow[t]{2}{*}{ Control Group } & \multicolumn{3}{|c|}{ Treatment Group } \\
\hline & All & Compliers & Non-Compliers \\
\hline 0.121 & 0.124 & 0.076 & 0.173 \\
\hline 0.943 & 0.942 & 0.956 & 0.926 \\
\hline 0.035 & 0.035 & 0.026 & 0.045 \\
\hline 0.033 & 0.033 & 0.018 & 0.050 \\
\hline 0.004 & 0.005 & 0.002 & 0.008 \\
\hline 0.088 & 0.087 & 0.057 & 0.117 \\
\hline 1.254 & 1.253 & 1.208 & 1.298 \\
\hline 1.752 & 1.746 & 1.855 & 1.638 \\
\hline 32.023 & 32.116 & 30.624 & 33.615 \\
\hline 0.786 & 0.786 & 0.792 & 0.781 \\
\hline 0.059 & 0.060 & 0.061 & 0.058 \\
\hline 9.944 & 9.942 & 9.436 & 10.451 \\
\hline 0.409 & $0.395 * *$ & 0.505 & 0.285 \\
\hline 2,106 & 2,152 & 1,691 & 2,616 \\
\hline 0.562 & $0.572 *$ & 0.544 & 0.601 \\
\hline 0.600 & 0.593 & 0.714 & 0.471 \\
\hline 0.133 & $0.145^{*}$ & 0.147 & 0.142 \\
\hline 0.167 & 0.162 & 0.151 & 0.173 \\
\hline 0.109 & 0.110 & 0.091 & 0.129 \\
\hline 0.160 & 0.165 & 0.155 & 0.174 \\
\hline 0.819 & 0.820 & 0.848 & 0.790 \\
\hline 0.289 & 0.289 & 0.299 & 0.278 \\
\hline 84.8 & $83.2 * *$ & 86.1 & 80.3 \\
\hline 20.1 & 19.9 & 21.3 & 18.6 \\
\hline 682 & 678 & 671 & 687 \\
\hline 1,053 & 1,052 & 1,061 & 1,044 \\
\hline 30,662 & 11,696 & 5,863 & 5,833 \\
\hline & $\begin{array}{c}0.98 \\
0.4979\end{array}$ & & \\
\hline
\end{tabular}

Notes: The unit of analysis is the household head. The sample includes all working-age, able-bodied CHAC applicants who were living in private housing at

baseline. ** = significant at 5\% level, * = significant at 10\% level. All earnings, rent and FMR are measured in 2007 dollars. 
Table II: The Effect of Voucher Offer and Other Baseline Household Characteristics on Voucher Utilization

\begin{tabular}{|c|c|c|c|c|c|c|c|}
\hline & \multicolumn{2}{|c|}{$\begin{array}{c}\text { Treatment and Control } \\
\text { Households }\end{array}$} & \multicolumn{5}{|c|}{ Treatment Households Only } \\
\hline & $(1)$ & $(2)$ & (3) & $(4)$ & (5) & $(6)$ & $(7)$ \\
\hline HHH received a voucher offer in a prior quarter & $\begin{array}{l}0.399 * * \\
(0.005)\end{array}$ & & & & & & \\
\hline HHH ever received voucher offer & & $\begin{array}{c}0.426^{* *} \\
(0.005)\end{array}$ & & & & & \\
\hline HHH male & & & $\begin{array}{c}-0.222^{* *} \\
(0.013)\end{array}$ & & $\begin{array}{c}-0.125^{* *} \\
(0.014)\end{array}$ & $\begin{array}{c}-0.133^{* *} \\
(0.014)\end{array}$ & $\begin{array}{c}-0.132^{* *} \\
(0.014)\end{array}$ \\
\hline Age of $\mathrm{HHH}$ & & & $\begin{array}{c}-0.021^{* *} \\
(0.003)\end{array}$ & & $\begin{array}{c}-0.016^{* *} \\
(0.003)\end{array}$ & $\begin{array}{c}-0.016 * * \\
(0.003)\end{array}$ & $\begin{array}{r}-0.016 * * \\
(0.003)\end{array}$ \\
\hline Age (squared) of $\mathrm{HHH}$ & & & $\begin{array}{c}0.000^{* *} \\
(0.000)\end{array}$ & & $\begin{array}{c}0.000^{* *} \\
(0.000)\end{array}$ & $\begin{array}{l}0.000^{* *} \\
(0.000)\end{array}$ & $\begin{array}{c}0.000^{* *} \\
(0.000)\end{array}$ \\
\hline 2 people in $\mathrm{HH}$ & & & $\begin{array}{c}0.089 * * \\
(0.015)\end{array}$ & & $\begin{array}{c}0.006 \\
(0.015)\end{array}$ & $\begin{array}{c}0.005 \\
(0.015)\end{array}$ & $\begin{array}{c}0.004 \\
(0.015)\end{array}$ \\
\hline 3 people in $\mathrm{HH}$ & & & $\begin{array}{l}0.114^{* *} \\
(0.015)\end{array}$ & & $\begin{array}{c}0.018 \\
(0.016)\end{array}$ & $\begin{array}{c}0.016 \\
(0.015)\end{array}$ & $\begin{array}{c}0.016 \\
(0.015)\end{array}$ \\
\hline 4 people in $\mathrm{HH}$ & & & $\begin{array}{c}0.108 * * \\
(0.016)\end{array}$ & & $\begin{array}{c}0.018 \\
(0.018)\end{array}$ & $\begin{array}{c}0.012 \\
(0.017)\end{array}$ & $\begin{array}{c}0.012 \\
(0.017)\end{array}$ \\
\hline 5+ people in $\mathrm{HH}$ & & & $\begin{array}{c}0.096^{* *} \\
(0.017) \\
\end{array}$ & & $\begin{array}{c}-0.005 \\
(0.018)\end{array}$ & $\begin{array}{l}-0.009 \\
(0.018)\end{array}$ & $\begin{array}{c}-0.009 \\
(0.018)\end{array}$ \\
\hline HHH employed 1997q2 & & & $\begin{array}{c}-0.058 * * \\
(0.009)\end{array}$ & & $\begin{array}{l}0.101^{* *} \\
(0.013)\end{array}$ & $\begin{array}{l}0.105 * * \\
(0.012)\end{array}$ & $\begin{array}{c}0.105^{* *} \\
(0.012)\end{array}$ \\
\hline HHH receiving TANF 1997q2 & & & $\begin{array}{c}0.230^{* *} \\
(0.009)\end{array}$ & & $\begin{array}{c}0.057 * * \\
(0.014)\end{array}$ & $\begin{array}{c}0.066^{* *} \\
(0.013)\end{array}$ & $\begin{array}{c}0.066 * * \\
(0.013)\end{array}$ \\
\hline HHH receiving TANF, Med, or FS 1997q2 & & & $\begin{array}{c}0.251^{* *} \\
(0.009)\end{array}$ & & $\begin{array}{l}0.129 * * \\
(0.014)\end{array}$ & $\begin{array}{l}0.130^{* *} \\
(0.013)\end{array}$ & $\begin{array}{c}0.129 * * \\
(0.013)\end{array}$ \\
\hline HHH wage (2007\$) 1997q2 (\$1,000s) & & & $\begin{array}{c}-0.031^{* *} \\
(0.02)\end{array}$ & & $\begin{array}{c}-0.023^{* *} \\
(0.002)\end{array}$ & $\begin{array}{c}-0.023^{* *} \\
(0.002)\end{array}$ & $\begin{array}{c}-0.023^{* *} \\
(0.002)\end{array}$ \\
\hline Combined HH earnings 1997q2 (\$1,000s) & & & $\begin{array}{c}-0.006^{* *} \\
(0.00)\end{array}$ & & & & \\
\hline Poverty rate in census tract & & & $\begin{array}{c}0.009^{* *} \\
(0.035)\end{array}$ & $\begin{array}{c}0.214^{* *} \\
(0.044)\end{array}$ & & $\begin{array}{c}0.126 * * \\
(0.042)\end{array}$ & $\begin{array}{c}0.129 * * \\
(0.042)\end{array}$ \\
\hline Census tract violent crime rate (crimes per 100,000 residents) & & & $\begin{array}{c}0.227^{* *} \\
(0.035)\end{array}$ & $\begin{array}{c}0.139 \\
(0.049)\end{array}$ & & $\begin{array}{l}0.089 * * \\
(0.042)\end{array}$ & $\begin{array}{c}0.086 * * \\
(0.042)\end{array}$ \\
\hline Census tract property crime (crimes per 100,000 residents) & & & $\begin{array}{c}0.011^{* *} \\
(0.07)\end{array}$ & $\begin{array}{c}0.010^{* *} \\
(0.014)\end{array}$ & & $\begin{array}{c}-0.004^{* *} \\
(0.008)\end{array}$ & $\begin{array}{c}-0.003^{* *} \\
(0.007)\end{array}$ \\
\hline Census tract social capital & & & $\begin{array}{c}-0.070^{* *} \\
(0.029)\end{array}$ & $\begin{array}{c}0.008 \\
(0.031)\end{array}$ & & $\begin{array}{l}-0.017 \\
(0.029)\end{array}$ & $\begin{array}{l}-0.016 \\
(0.029)\end{array}$ \\
\hline Missing census tract & & & $\begin{array}{c}-0.161^{* *} \\
(0.016)\end{array}$ & $\begin{array}{l}-0.051 \\
(0.114)\end{array}$ & & $\begin{array}{l}-0.149 \\
(0.108)\end{array}$ & $\begin{array}{l}-0.143 \\
(0.108)\end{array}$ \\
\hline HHH offered voucher in 2000 & & & $\begin{array}{c}-0.054^{* *} \\
(0.015)\end{array}$ & & & & $\begin{array}{c}-0.056^{* *} \\
(0.014)\end{array}$ \\
\hline HHH offered voucher in 2001 & & & $\begin{array}{c}-0.032^{* *} \\
(0.012)\end{array}$ & & & & $\begin{array}{c}-0.033^{* *} \\
(0.012)\end{array}$ \\
\hline HHH offered voucher in 2002 & & & $\begin{array}{c}0.018 \\
(0.013)\end{array}$ & & & & $\begin{array}{c}0.015 \\
(0.012)\end{array}$ \\
\hline HHH offered voucher in 2003 & & & $\begin{array}{c}-0.060^{*} \\
(0.031)\end{array}$ & & & & $\begin{array}{l}-0.048 \\
(0.031)\end{array}$ \\
\hline Control Group Mean & 0.053 & .076 & & & & & \\
\hline Treatment Group Mean & & & 0.501 & 0.501 & 0.501 & 0.501 & 0.501 \\
\hline Number of households & 42,358 & 42,358 & 11,696 & 11,696 & 11,696 & 11,696 & 11,696 \\
\hline $\begin{array}{l}\text { Number of observations } \\
\text { Census tract fixed effects }\end{array}$ & $1,440,172$ & 42,358 & 11,696 & 11,696 & $\begin{array}{c}11,696 \\
\text { Yes }\end{array}$ & 11,696 & 11,696 \\
\hline R-squared & 0.262 & 0.276 & varies & 0.014 & 0.155 & 0.100 & 0.103 \\
\hline F-Test (Neighborhood characteristics or tract dummies) & $7,567.10$ & $8,280.88$ & & 34.67 & 998.34 & 22.65 & 22.26 \\
\hline p-value (Neighborhood characteristics or tract dummies) & {$[0.000]$} & [0.000] & & {$[0.000]$} & {$[0.000]$} & {$[0.000]$} & {$[0.000]$} \\
\hline $\begin{array}{l}\text { F-Test (person characteristics) } \\
\text { p-value (person characteristics) } \\
\text { F-Test (offer year) } \\
\text { p-value (offer year) }\end{array}$ & & & & & $\begin{array}{c}95.08 \\
{[0.000]}\end{array}$ & $\begin{array}{c}113.71 \\
{[0.000]}\end{array}$ & $\begin{array}{c}114.08 \\
{[0.000]} \\
8.71 \\
{[0.000]}\end{array}$ \\
\hline
\end{tabular}

Notes: The dependent variable for column (1) is ever used a voucher in prior quarter. For columns (2) - (7), it is ever used a voucher over the sample period. The unit of observation for column (1) is person-year-quarter, and for columns (2) - (7), it is person. Column (3) runs separate bivariate regressions. Each of the four census tract bivariate regressions include missing tract. Census tract dummies are included in column (5). For column (1), robust standard errors are clustered at household level. For columns (2) - (7), robust standard errors are presented. The sample includes all working-age, able-bodied CHAC applicants who were living in private housing at baseline. ** = significant at 5\% level. * = significant at 10\%. All earnings are measured in 2007 dollars. 
Table III: Effects Of Housing Vouchers On Household Heads

\begin{tabular}{|c|c|c|c|c|c|}
\hline & $\mathrm{CM}$ & ITT & IV & CCM & $\begin{array}{l}\text { Number of } \\
\text { Households }\end{array}$ \\
\hline HHH employed & 0.592 & $\begin{array}{c}-0.014^{* *} \\
(0.004)\end{array}$ & $\begin{array}{c}-0.036^{* *} \\
(0.009)\end{array}$ & 0.605 & 42,358 \\
\hline HHH earnings & 3,291.02 & $\begin{array}{c}-128.44 * * \\
(30.617)\end{array}$ & $\begin{array}{c}-327.96 * * \\
(74.585)\end{array}$ & $3,112.90$ & 42,358 \\
\hline HHH earnings > \$2,415 (FT@\$6/hr) & 0.464 & $\begin{array}{c}-0.018^{* *} \\
(0.004)\end{array}$ & $\begin{array}{c}-0.045^{* *} \\
(0.009)\end{array}$ & 0.470 & 42,358 \\
\hline HHH earnings conditional on working & $5,557.98$ & $\begin{array}{l}-91.48^{* *} \\
(34.099)\end{array}$ & $\begin{array}{c}-228.44 * * \\
(80.236)\end{array}$ & $5,129.26$ & 38,628 \\
\hline HHH log earnings conditional on working & 8.279 & $\begin{array}{c}-0.029 * * \\
(0.008)\end{array}$ & $\begin{array}{c}-0.073^{* *} \\
(0.018)\end{array}$ & 8.220 & 38,628 \\
\hline HHH received public assistance & 0.460 & $\begin{array}{c}0.027 * * \\
(0.004)\end{array}$ & $\begin{array}{c}0.067 * * \\
(0.009)\end{array}$ & 0.552 & 42,358 \\
\hline HHH received TANF & 0.146 & $\begin{array}{c}0.006 * * \\
(0.002)\end{array}$ & $\begin{array}{c}0.016^{* *} \\
(0.004)\end{array}$ & 0.110 & 42,358 \\
\hline HHH received Medicaid & 0.400 & $\begin{array}{c}0.023 * * \\
(0.004)\end{array}$ & $\begin{array}{c}0.058^{* *} \\
(0.009)\end{array}$ & 0.484 & 42,358 \\
\hline HHH received Food Stamps & 0.375 & $\begin{array}{c}0.030^{* *} \\
(0.003)\end{array}$ & $\begin{array}{c}0.076^{* *} \\
(0.008)\end{array}$ & 0.450 & 42,358 \\
\hline
\end{tabular}

Notes: The unit of observation is person-year-quarter. The sample includes all working-age, able-bodied CHAC applicants who were living in private housing at baseline. $\mathrm{CM}=$ Control Mean. ITT $=$ Intent-to-Treat. IV = Instrumental Variables. CCM = Control Complier Mean. See text for discussion of these estimates. Robust standard errors clustered at household level. ** = significant at 5\% level, * = significant at 10\% level. All earnings are measured in 2007 dollars. 
Table IV: Housing Voucher Effects by Subgroup

\begin{tabular}{|c|c|c|c|c|c|c|c|c|c|}
\hline & \multirow{2}{*}{$\begin{array}{l}\text { Number of } \\
\text { Households }\end{array}$} & \multicolumn{4}{|c|}{ Employed } & \multicolumn{4}{|c|}{$\underline{\text { Received public assistance }}$} \\
\hline & & $\mathrm{CM}$ & ITT & IV & $\mathrm{CCM}$ & $\mathrm{CM}$ & ITT & IV & CCM \\
\hline Baseline (all working-age and able-bodied) & 42,358 & 0.592 & $\begin{array}{c}-0.014 * * \\
(0.004)\end{array}$ & $\begin{array}{c}-0.036^{* *} \\
(0.009)\end{array}$ & 0.605 & 0.460 & $\begin{array}{c}0.027^{* *} \\
(0.004)\end{array}$ & $\begin{array}{c}0.067 * * \\
(0.009)\end{array}$ & 0.552 \\
\hline Elderly (65+ yrs old) & 2,002 & 0.051 & $\begin{array}{l}-0.001 \\
(0.006)\end{array}$ & $\begin{array}{c}0.001 \\
(0.024)\end{array}$ & 0.028 & 0.509 & $\begin{array}{c}0.000 \\
(0.017)\end{array}$ & $\begin{array}{c}-0.018 \\
(0.071)\end{array}$ & 0.686 \\
\hline Disabled & 15,237 & 0.274 & $\begin{array}{l}-0.001 \\
(0.005)\end{array}$ & $\begin{array}{l}-0.005 \\
(0.012)\end{array}$ & 0.288 & 0.602 & $\begin{array}{l}0.012^{*} \\
(0.006)\end{array}$ & $\begin{array}{l}0.029 * \\
(0.015)\end{array}$ & 0.688 \\
\hline \multicolumn{10}{|l|}{ Among working-age and able-bodied sample: } \\
\hline Male & 5,120 & 0.519 & $\begin{array}{l}-0.003 \\
(0.010)\end{array}$ & $\begin{array}{l}-0.018 \\
(0.043)\end{array}$ & 0.470 & 0.234 & $\begin{array}{c}0.018^{* *} \\
(0.009)\end{array}$ & $\begin{array}{c}0.076^{* *} \\
(0.038)\end{array}$ & 0.323 \\
\hline Female & 37,238 & 0.602 & $\begin{array}{c}-0.016 * * \\
(0.004)\end{array}$ & $\begin{array}{c}-0.038 * * \\
(0.009)\end{array}$ & 0.615 & 0.491 & $\begin{array}{c}0.029 * * \\
(0.004)\end{array}$ & $\begin{array}{c}0.067 * * \\
(0.009)\end{array}$ & 0.570 \\
\hline Employed in 1997q2 & 23,934 & 0.748 & $\begin{array}{c}-0.015^{* *} \\
(0.005)\end{array}$ & $\begin{array}{c}-0.039 * * \\
(0.011)\end{array}$ & 0.718 & 0.352 & $\begin{array}{c}0.028 * * \\
(0.005)\end{array}$ & $\begin{array}{c}0.071^{* *} \\
(0.011)\end{array}$ & 0.454 \\
\hline Not employed in 1997q2 & 18,424 & 0.392 & $\begin{array}{c}-0.011^{* *} \\
(0.006)\end{array}$ & $\begin{array}{c}-0.030^{* *} \\
(0.014)\end{array}$ & 0.469 & 0.599 & $\begin{array}{c}0.025^{* *} \\
(0.006)\end{array}$ & $\begin{array}{c}0.061^{* *} \\
(0.013)\end{array}$ & 0.669 \\
\hline Receiving some form of public assistance in 1997q2 & 25,317 & 0.544 & $\begin{array}{c}-0.011^{* *} \\
(0.005)\end{array}$ & $\begin{array}{c}-0.025^{* *} \\
(0.010)\end{array}$ & 0.576 & 0.653 & $\begin{array}{c}0.027^{* *} \\
(0.005)\end{array}$ & $\begin{array}{c}0.056^{* *} \\
(0.010)\end{array}$ & 0.654 \\
\hline Not receiving any public assistance in 1997q2 & 17,041 & 0.664 & $\begin{array}{c}-0.017^{* *} \\
(0.005)\end{array}$ & $\begin{array}{c}-0.061^{* *} \\
(0.019)\end{array}$ & 0.673 & 0.172 & $\begin{array}{c}0.027^{* *} \\
(0.005)\end{array}$ & $\begin{array}{c}0.095 * * \\
(0.017)\end{array}$ & 0.281 \\
\hline No Kids in $\mathrm{HH}$ & 8,137 & 0.563 & $\begin{array}{c}-0.017 * * \\
(0.008)\end{array}$ & $\begin{array}{c}-0.058^{* *} \\
(0.027)\end{array}$ & 0.545 & 0.299 & $\begin{array}{c}0.031^{* *} \\
(0.008)\end{array}$ & $\begin{array}{c}0.109^{* *} \\
(0.026)\end{array}$ & 0.392 \\
\hline One Kid in $\mathrm{HH}$ & 12,650 & 0.630 & $\begin{array}{c}-0.019 * * \\
(0.007)\end{array}$ & $\begin{array}{c}-0.046^{* *} \\
(0.016)\end{array}$ & 0.628 & 0.432 & $\begin{array}{c}0.025^{* *} \\
(0.007)\end{array}$ & $\begin{array}{c}0.061^{* *} \\
(0.016)\end{array}$ & 0.545 \\
\hline Two Kids in $\mathrm{HH}$ & 11,053 & 0.608 & $\begin{array}{c}-0.016^{* *} \\
(0.007)\end{array}$ & $\begin{array}{c}-0.038^{* *} \\
(0.016)\end{array}$ & 0.631 & 0.492 & $\begin{array}{c}0.028^{* *} \\
(0.007)\end{array}$ & $\begin{array}{c}0.063^{* *} \\
(0.015)\end{array}$ & 0.554 \\
\hline Three+ Kids in $\mathrm{HH}$ & 10,518 & 0.552 & $\begin{array}{l}-0.006 \\
(0.007)\end{array}$ & $\begin{array}{l}-0.015 \\
(0.016)\end{array}$ & 0.586 & 0.586 & $\begin{array}{c}0.026 * * \\
(0.007)\end{array}$ & $\begin{array}{c}0.058^{* *} \\
(0.016)\end{array}$ & 0.643 \\
\hline Below median poverty rate in census tract & 19,312 & 0.602 & $\begin{array}{c}-0.017^{* *} \\
(0.005)\end{array}$ & $\begin{array}{c}-0.045^{* *} \\
(0.013)\end{array}$ & 0.603 & 0.419 & $\begin{array}{c}0.035 * * \\
(0.005)\end{array}$ & $\begin{array}{c}0.088^{* *} \\
(0.013)\end{array}$ & 0.524 \\
\hline Above median poverty rate in census tract & 19,474 & 0.577 & $\begin{array}{c}-0.011^{* *} \\
(0.005)\end{array}$ & $\begin{array}{c}-0.027^{* *} \\
(0.012)\end{array}$ & 0.601 & 0.515 & $\begin{array}{c}0.022 * * \\
(0.005)\end{array}$ & $\begin{array}{c}0.051^{* *} \\
(0.012)\end{array}$ & 0.581 \\
\hline Offer Cohort 1997-1998 & 33,641 & 0.592 & $\begin{array}{c}-0.029^{* *} \\
(0.006)\end{array}$ & $\begin{array}{c}-0.068^{* *} \\
(0.013)\end{array}$ & 0.643 & 0.460 & $\begin{array}{c}0.036^{* *} \\
(0.006)\end{array}$ & $\begin{array}{c}0.083^{* *} \\
(0.013)\end{array}$ & 0.544 \\
\hline Offer Cohort 2000-2001 & 36,126 & 0.592 & $\begin{array}{l}-0.003 \\
(0.005)\end{array}$ & $\begin{array}{l}-0.010 \\
(0.014)\end{array}$ & 0.581 & 0.460 & $\begin{array}{c}0.024 * * \\
(0.005)\end{array}$ & $\begin{array}{c}0.064^{* *} \\
(0.013)\end{array}$ & 0.556 \\
\hline Offer Cohort 2002-2003 & 33,915 & 0.592 & $\begin{array}{l}-0.010 \\
(0.007)\end{array}$ & $\begin{array}{l}-0.023 \\
(0.016)\end{array}$ & 0.576 & 0.460 & $\begin{array}{c}0.019 * * \\
(0.007) \\
\end{array}$ & $\begin{array}{c}0.042^{* *} \\
(0.015) \\
\end{array}$ & 0.561 \\
\hline
\end{tabular}

Notes: The unit of observation is person-year-quarter. The sample varies across the rows based on the subsample. CM $=$ Control Mean. ITT $=$ Intent-to-Treat. IV $=$ Instrumental

Variables. CCM $=$ Control Complier Mean. See text for discussion of these estimates. Robust standard errors clustered at household level. $* *=$ significant at $5 \%$ level, $*=$ significant at $10 \%$ level. 
Table V: Effects of a Voucher Offer on Residential Stability and Neighborhood Environment

\begin{tabular}{|c|c|c|c|c|c|}
\hline & CM & ITT & IV & CCM & $\begin{array}{c}\text { Number of } \\
\text { Households }\end{array}$ \\
\hline Number of different residential addresses & 2.668 & $\begin{array}{c}0.038 \\
(0.047)\end{array}$ & $\begin{array}{c}0.124 \\
(0.117)\end{array}$ & 3.176 & 4,184 \\
\hline Poverty rate & 0.257 & $\begin{array}{l}-0.004 \\
(0.004)\end{array}$ & $\begin{array}{l}-0.011 \\
(0.011)\end{array}$ & 0.275 & 3,944 \\
\hline Poverty rate below $20 \%$ & 0.395 & $\begin{array}{c}0.008 \\
(0.015)\end{array}$ & $\begin{array}{c}0.017 \\
(0.035)\end{array}$ & 0.338 & 4,138 \\
\hline Fraction black & 0.779 & $\begin{array}{c}0.002 \\
(0.008)\end{array}$ & $\begin{array}{c}0.004 \\
(0.019)\end{array}$ & 0.810 & 3,944 \\
\hline Collective efficacy score & 3.778 & $\begin{array}{c}0.000 \\
(0.007)\end{array}$ & $\begin{array}{c}0.001 \\
(0.015)\end{array}$ & 3.770 & 3,860 \\
\hline Social capital score & 3.501 & $\begin{array}{l}-0.005 \\
(0.005)\end{array}$ & $\begin{array}{l}-0.011 \\
(0.011)\end{array}$ & 3.509 & 3,860 \\
\hline Property crime arrest rate & 74.685 & $\begin{array}{l}-0.546 \\
(0.885)\end{array}$ & $\begin{array}{l}-1.262 \\
(2.012)\end{array}$ & 71.424 & 3,682 \\
\hline Violent crime arrest rate & 16.687 & $\begin{array}{l}-0.128 \\
(0.240)\end{array}$ & $\begin{array}{l}-0.288 \\
(0.552)\end{array}$ & 15.693 & 3,682 \\
\hline
\end{tabular}

Notes: The unit of observation is person-year-quarter. The sample includes all working-age, able-bodied CHAC applicants who were living in private housing at baseline. $\mathrm{CM}=$ Control Mean. ITT $=$ Intent-to-Treat. IV = Instrumental Variables. CCM = Control Complier Mean. See text for discussion of these estimates. Robust standard errors clustered at household level. **= significant at $5 \%$ level, * = significant at $10 \%$ level. 
Table VI: Nonexperimental Estimates of the Effect of Housing Vouchers on Labor Market Outcomes

\begin{tabular}{|c|c|c|c|c|c|c|}
\hline \multirow{3}{*}{$\begin{array}{l}\text { Control Group Non-Experimental Estimates } \\
\text { HHH employed }\end{array}$} & $(1)$ & $(2)$ & $(3)$ & $(4)$ & (5) & $(6)$ \\
\hline & & & & & & \\
\hline & 30,750 & 0.595 & $\begin{array}{c}-0.036 * * \\
(0.009)\end{array}$ & $\begin{array}{c}-0.068 * * \\
(0.008)\end{array}$ & $\begin{array}{l}-0.004 \\
(0.007)\end{array}$ & $\begin{array}{c}0.003 \\
(0.009)\end{array}$ \\
\hline HHH earnings & 30,750 & 3,348.98 & $\begin{array}{c}-327.96 * * \\
(74.585)\end{array}$ & $\begin{array}{l}-1,114.18^{* *} \\
(55.498)\end{array}$ & $\begin{array}{c}-307.75 * * \\
(49.040)\end{array}$ & $\begin{array}{l}-89.94^{*} \\
(49.445)\end{array}$ \\
\hline HHH earnings > \$2415 (FT@\$6/hr) & 30,750 & 0.470 & $\begin{array}{c}-0.045^{* *} \\
(0.009)\end{array}$ & $\begin{array}{c}-0.111^{* *} \\
(0.008)\end{array}$ & $\begin{array}{c}-0.027 * * \\
(0.007)\end{array}$ & $\begin{array}{c}0.024^{* *} \\
(0.008)\end{array}$ \\
\hline HHH earnings > \$3220 (FT@\$8/hr) & 30,750 & 0.426 & $\begin{array}{c}-0.046 * * \\
(0.009)\end{array}$ & $\begin{array}{c}-0.119 * * \\
(0.008)\end{array}$ & $\begin{array}{c}-0.030 * * \\
(0.007)\end{array}$ & $\begin{array}{c}0.021^{* *} \\
(0.008)\end{array}$ \\
\hline HHH earnings conditional on working & 28,030 & $5,624.65$ & $\begin{array}{c}-228.44^{* *} \\
(80.236)\end{array}$ & $\begin{array}{c}-1,388.76^{* *} \\
(64.830)\end{array}$ & $\begin{array}{c}-515.36^{* *} \\
(58.505)\end{array}$ & $\begin{array}{c}-235.66 * * \\
(63.837)\end{array}$ \\
\hline HHH log earnings conditional on working & 28,030 & 8.296 & $\begin{array}{c}-0.073^{* *} \\
(0.018)\end{array}$ & $\begin{array}{c}-0.347 * * \\
(0.019)\end{array}$ & $\begin{array}{l}-0.123^{* *} \\
(0.017)\end{array}$ & $\begin{array}{l}-0.009 \\
(0.024)\end{array}$ \\
\hline HHH received public assistance & 30,750 & 0.448 & $\begin{array}{r}0.067^{* *} \\
(0.009)\end{array}$ & $\begin{array}{c}0.224^{* *} \\
(0.008)\end{array}$ & $\begin{array}{l}0.104 * * \\
(0.007)\end{array}$ & $\begin{array}{c}0.081^{* *} \\
(0.009)\end{array}$ \\
\hline $\mathrm{HHH}$ received TANF & 30,750 & 0.144 & $\begin{array}{c}0.016^{* *} \\
(0.004)\end{array}$ & $\begin{array}{c}0.039 * * \\
(0.005)\end{array}$ & $\begin{array}{c}0.017^{* *} \\
(0.004)\end{array}$ & $\begin{array}{c}-0.083^{* *} \\
(0.009)\end{array}$ \\
\hline HHH received Medicaid & 30,750 & 0.388 & $\begin{array}{c}0.058^{* *} \\
(0.009)\end{array}$ & $\begin{array}{c}0.206^{* *} \\
(0.009)\end{array}$ & $\begin{array}{c}0.091^{* *} \\
(0.007)\end{array}$ & $\begin{array}{c}0.075^{* *} \\
(0.009)\end{array}$ \\
\hline HHH received Food Stamps & 30,750 & 0.363 & $\begin{array}{c}0.076 * * \\
(0.008)\end{array}$ & $\begin{array}{c}0.211^{* *} \\
(0.008)\end{array}$ & $\begin{array}{c}0.109 * * \\
(0.007)\end{array}$ & $\begin{array}{c}0.071^{* *} \\
(0.009)\end{array}$ \\
\hline \multicolumn{7}{|l|}{ Treatment Group Non-Experimental Estimates } \\
\hline HHH employed & 11,725 & 0.596 & $\begin{array}{c}-0.036 * * \\
(0.009)\end{array}$ & $\begin{array}{c}-0.027 * * \\
(0.006)\end{array}$ & $\begin{array}{c}0.029 * * \\
(0.006)\end{array}$ & $\begin{array}{c}0.006 \\
(0.005)\end{array}$ \\
\hline HHH earnings & 11,725 & $3,463.46$ & $\begin{array}{c}-327.96 * * \\
(74.585)\end{array}$ & $\begin{array}{c}-676.32 * * \\
(49.079)\end{array}$ & $\begin{array}{c}-300.69 * * \\
(46.899)\end{array}$ & $\begin{array}{c}-0.32 \\
(37.681)\end{array}$ \\
\hline HHH earnings > \$2,415 (FT@\$6/hr) & 11,725 & 0.473 & $\begin{array}{c}-0.045^{* *} \\
(0.009)\end{array}$ & $\begin{array}{c}-0.048 * * \\
(0.006)\end{array}$ & $\begin{array}{c}0.005 \\
(0.006)\end{array}$ & $\begin{array}{c}0.019 * * \\
(0.005)\end{array}$ \\
\hline HHH earnings > \$3,220 (FT@\$8/hr) & 11,725 & 0.431 & $\begin{array}{c}-0.046^{* *} \\
(0.009)\end{array}$ & $\begin{array}{c}-0.056^{* *} \\
(0.006)\end{array}$ & $\begin{array}{c}-0.004 \\
(0.006)\end{array}$ & $\begin{array}{c}0.023^{* *} \\
(0.005)\end{array}$ \\
\hline HHH earnings conditional on working & 10,685 & $5,812.37$ & $\begin{array}{c}-228.44 * * \\
(80.236)\end{array}$ & $\begin{array}{c}-909.19 * * \\
(53.669)\end{array}$ & $\begin{array}{c}-762.68^{* *} \\
(52.760)\end{array}$ & $\begin{array}{c}-200.73 * * \\
(41.879)\end{array}$ \\
\hline HHH log earnings conditional on working & 10,685 & 8.325 & $\begin{array}{c}-0.073 * * \\
(0.018)\end{array}$ & $\begin{array}{c}-0.177^{* *} \\
(0.013)\end{array}$ & $\begin{array}{c}-0.122 * * \\
(0.013)\end{array}$ & $\begin{array}{c}0.003 \\
(0.012)\end{array}$ \\
\hline HHH received public assistance & 11,725 & 0.412 & $\begin{array}{c}0.067 * * \\
(0.009)\end{array}$ & $\begin{array}{c}0.207 * * \\
(0.006)\end{array}$ & $\begin{array}{c}0.148 * * \\
(0.006)\end{array}$ & $\begin{array}{c}0.043 * * \\
(0.006)\end{array}$ \\
\hline HHH received TANF & 11,725 & 0.152 & $\begin{array}{c}0.016^{* *} \\
(0.004)\end{array}$ & $\begin{array}{c}-0.025 * * \\
(0.003)\end{array}$ & $\begin{array}{c}0.011^{* *} \\
(0.003)\end{array}$ & $\begin{array}{c}-0.077^{* *} \\
(0.005)\end{array}$ \\
\hline HHH received Medicaid & 11,725 & 0.353 & $\begin{array}{c}0.058^{* *} \\
(0.009)\end{array}$ & $\begin{array}{c}0.189 * * \\
(0.006)\end{array}$ & $\begin{array}{c}0.135^{* *} \\
(0.006)\end{array}$ & $\begin{array}{c}0.035^{* *} \\
(0.006)\end{array}$ \\
\hline HHH received Food Stamps & 11,725 & 0.329 & $\begin{array}{c}0.076^{* *} \\
(0.008)\end{array}$ & $\begin{array}{c}0.197 * * \\
(0.006)\end{array}$ & $\begin{array}{c}0.142^{* *} \\
(0.006)\end{array}$ & $\begin{array}{c}0.046 * * \\
(0.006)\end{array}$ \\
\hline
\end{tabular}

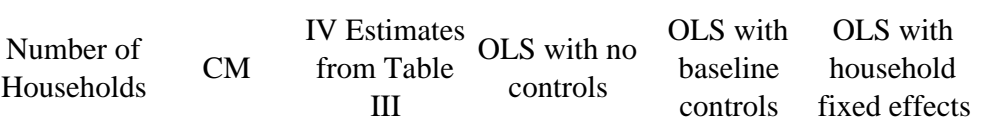

Notes: The unit of observation is person-year-quarter. The sample includes all working-age, able-bodied CHAC applicants who were living in private housing at baseline. $\mathrm{CM}=$ Control Mean (the mean for the non-experimental control group). See text for discussion of these estimates. Robust standard errors clustered at household level. $* *=$ significant at $5 \%$ level, $*=$ significant at $10 \%$ level. All earnings are in 2007 dollars. All specifications include year-quarter dummies. 
Dependent Variable = ITT Effect of Voucher Offer on Employment

\begin{tabular}{|c|c|c|c|c|c|c|}
\hline & $(1)$ & $(2)$ & (3) & (4) & (5) & (6) \\
\hline $\begin{array}{l}\text { Difference in treatment cohort and } \\
\text { control fraction leased up }\end{array}$ & $\begin{array}{c}-0.038^{* *} \\
(0.011)\end{array}$ & & & $\begin{array}{c}-0.038 * * \\
(0.011)\end{array}$ & & $\begin{array}{c}-0.037 * * \\
(0.012)\end{array}$ \\
\hline Years since offer & & $\begin{array}{l}-0.002 * \\
(0.001)\end{array}$ & & & $\begin{array}{l}-0.001 \\
(0.001)\end{array}$ & $\begin{array}{l}-0.000 \\
(0.001)\end{array}$ \\
\hline Contemperaneous unemployment rate & & & $\begin{array}{l}-0.002 \\
(0.001)\end{array}$ & $\begin{array}{l}-0.001 \\
(0.001)\end{array}$ & $\begin{array}{l}-0.002 \\
(0.001)\end{array}$ & $\begin{array}{l}-0.001 \\
(0.001)\end{array}$ \\
\hline $\begin{array}{l}\text { Unemployment rate in year surrounding } \\
\text { offer quarter }\end{array}$ & & & $\begin{array}{c}0.006 \\
(0.003)\end{array}$ & $\begin{array}{l}0.006^{*} \\
(0.003)\end{array}$ & $\begin{array}{c}0.005 \\
(0.004)\end{array}$ & $\begin{array}{l}0.006^{*} \\
(0.004)\end{array}$ \\
\hline $\begin{array}{l}\text { Mean of the dependent variable } \\
\text { Number of observations } \\
\text { p-value from the test of the } \\
\text { overidentifying restrictions }\end{array}$ & $\begin{array}{c}-0.017 \\
405 \\
0.1022\end{array}$ & $\begin{array}{c}-0.017 \\
405 \\
0.0598\end{array}$ & $\begin{array}{c}-0.017 \\
405\end{array}$ & $\begin{array}{c}-0.017 \\
405\end{array}$ & $\begin{array}{c}-0.017 \\
405\end{array}$ & $\begin{array}{c}-0.017 \\
405 \\
0.1049\end{array}$ \\
\hline & $\begin{array}{c}\text { Dependen } \\
\text { (1) }\end{array}$ & $\begin{array}{c}\text { ariable }= \\
(2)\end{array}$ & $\begin{array}{c}\text { Effect of } \\
\text { (3) }\end{array}$ & $\begin{array}{c}\text { ucher Offe } \\
\text { (4) }\end{array}$ & $\begin{array}{l}\text { Any Pub } \\
\text { (5) }\end{array}$ & $\begin{array}{c}\text { Assistance } \\
(6)\end{array}$ \\
\hline $\begin{array}{l}\text { Difference in treatment cohort and } \\
\text { control fraction leased up }\end{array}$ & $\begin{array}{c}0.041^{* *} \\
(0.009)\end{array}$ & & & $\begin{array}{c}0.039 * * \\
(0.009)\end{array}$ & & $\begin{array}{c}0.022 * * \\
(0.010)\end{array}$ \\
\hline Years since offer & & $\begin{array}{c}0.006 * * \\
(0.001)\end{array}$ & & & $\begin{array}{c}0.006^{* *} \\
(0.001)\end{array}$ & $\begin{array}{c}0.005^{* *} \\
(0.001)\end{array}$ \\
\hline Contemperaneous unemployment rate & & & $\begin{array}{c}0.002 * * \\
(0.001)\end{array}$ & $\begin{array}{l}0.002 * \\
(0.001)\end{array}$ & $\begin{array}{l}0.002^{* *} \\
(0.001)\end{array}$ & $\begin{array}{l}0.002 * \\
(0.001)\end{array}$ \\
\hline $\begin{array}{l}\text { Unemployment rate in year surrounding } \\
\text { offer quarter }\end{array}$ & & & $\begin{array}{l}-0.005 \\
(0.003)\end{array}$ & $\begin{array}{l}-0.006 \\
(0.003)\end{array}$ & $\begin{array}{l}-0.001 \\
(0.003)\end{array}$ & $\begin{array}{l}-0.002 \\
(0.003)\end{array}$ \\
\hline Mean of the dependent variable & 0.029 & 0.029 & 0.029 & 0.029 & 0.029 & 0.029 \\
\hline $\begin{array}{l}\text { Number of observations } \\
\text { p-value from the test of the }\end{array}$ & 405 & 405 & 405 & 405 & 405 & 405 \\
\hline overidentifying restrictions & 0.2460 & 0.4433 & 0.1289 & 0.2807 & 0.4829 & 0.5341 \\
\hline
\end{tabular}

Notes: The estimates in Table VII are GLS estimates, sometimes referred to as Optimal Minimum Distance (OMD) estimation (see Chamberlain, 1982). The dependent variable, the Intent-to-Treat (ITT) effect of a voucher offer on an outcome, is estimated in a first-stage regression of an indicator for employed-in-the-current-quarter on indicators for each quarter-relative-to-offer interacted with indicators for the quarter-year a voucher was offered, household- and tract-level control variables, and clustered at the household level. The estimates of the 405 treatment indicator coefficients and the associated variance-covariance matrix are used to implement second-stage GLS regressions with the vector of 405 ITT coefficients as the outcome. The reported p-value is from the efficient test of the restrictions of the second-stage model against the alternative of the fully interacted first-stage model. The sample includes all working-age, able-bodied CHAC applicants who were living in private housing at baseline. ${ }^{* *}=$ significant at $5 \%$ level, ${ }^{*}=$ significant at $10 \%$ level. 
Figure I: Budget Constraint With a Means-Tested Transfer




Figure II: ITT Effect Of Vouchers Over Time On Employment And Receipt Of Public Assistance

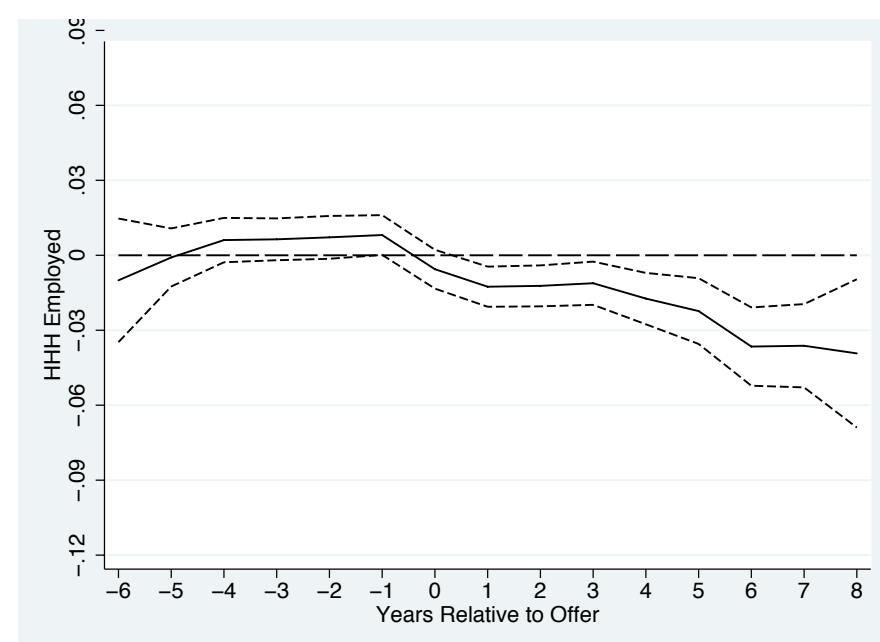

(a) HHH Employed

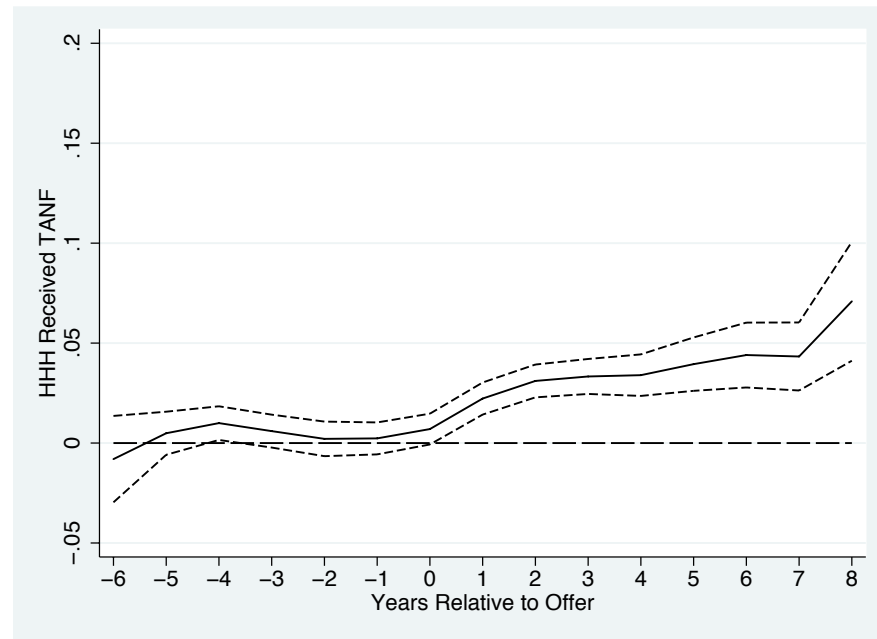

(c) HHH Receiving Any Public Assistance

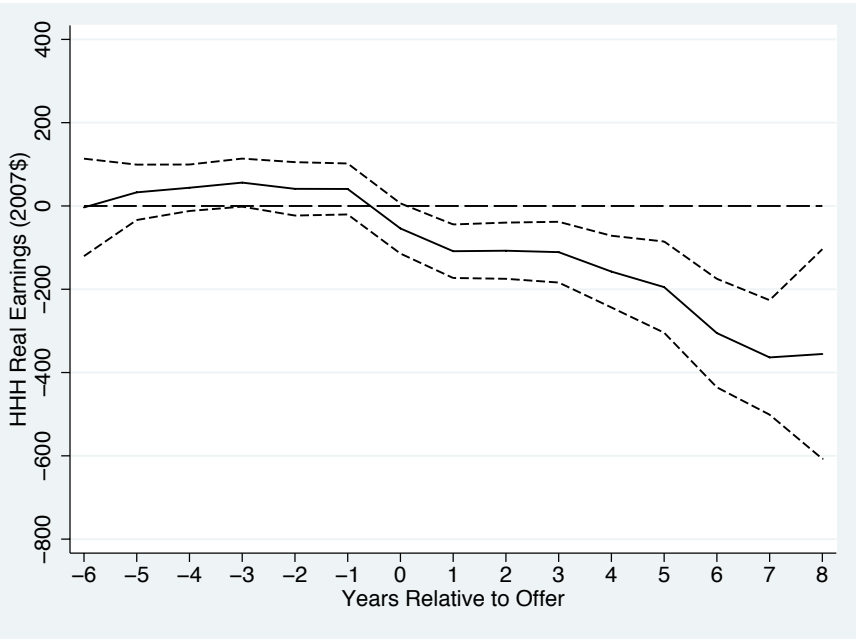

(b) HHH Real Earnings (2007\$)

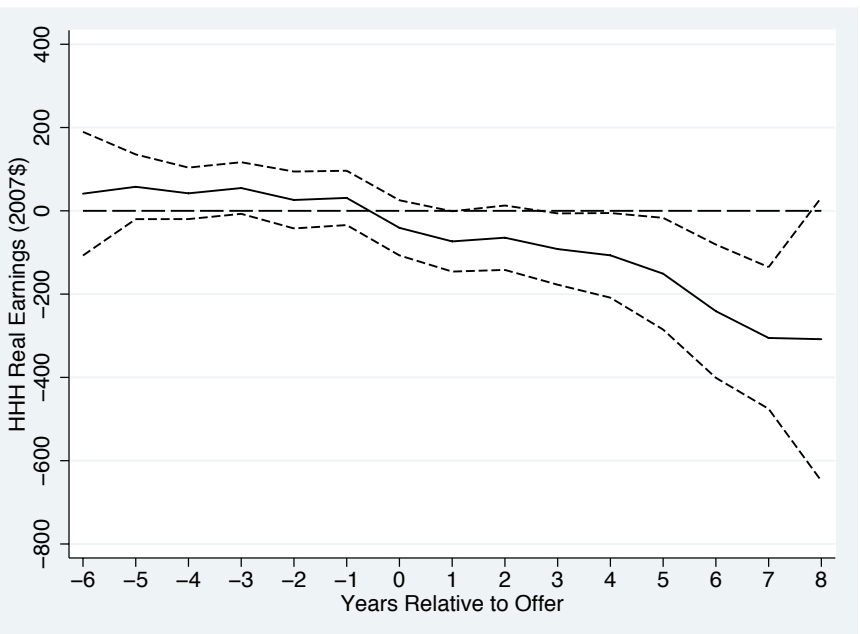

(d) HHH Conditional Earnings

Notes: Dotted lines represent the 95 percent confidence interval. Solid lines represent the point estimate. Estimates come from equation (4) in the text. Year zero is defined as the first full year after an offer, measured at the quarter level, and including the quarter of the offer. Sample includes all working-age, able-bodied CHAC applicants who were living in private housing at baseline. 
Figure III: ITT Effect Of Vouchers Over Time On Residential Stability and Neighborhood Environment

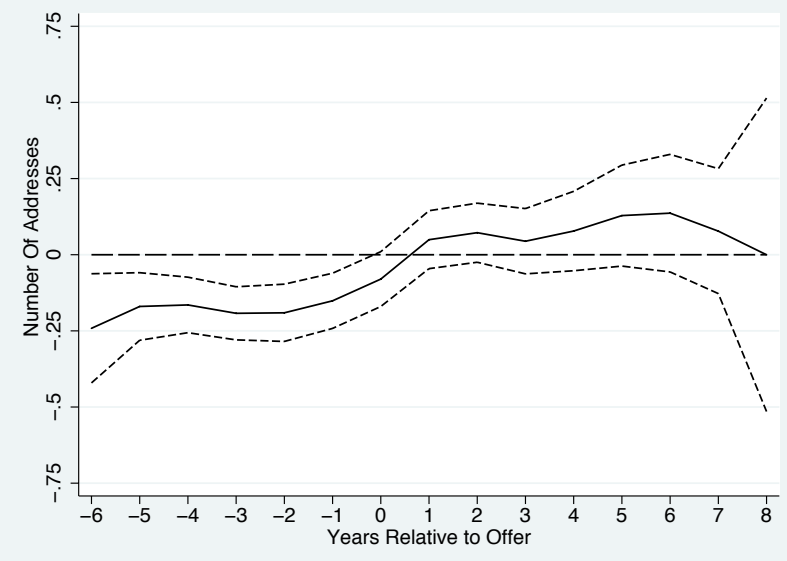

(a) Number Of Different Residential Addresses

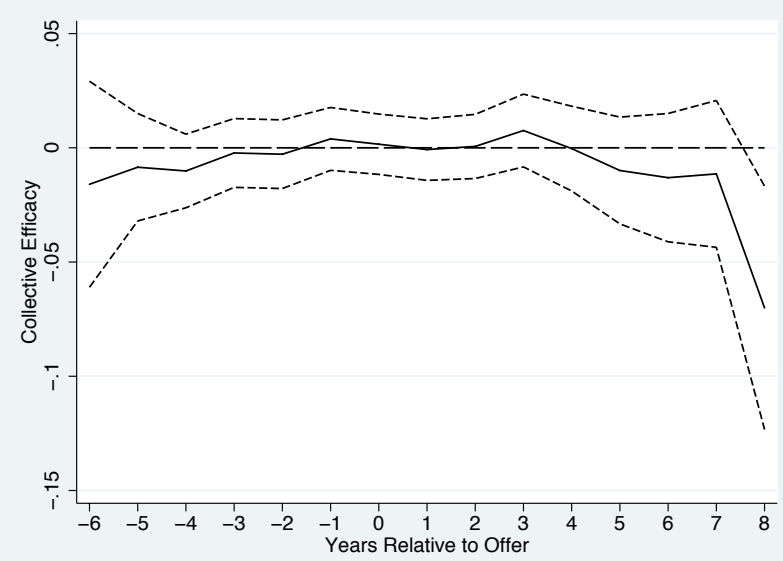

(c) Collective Efficacy Score



(e) Property Crime Arrest Rate

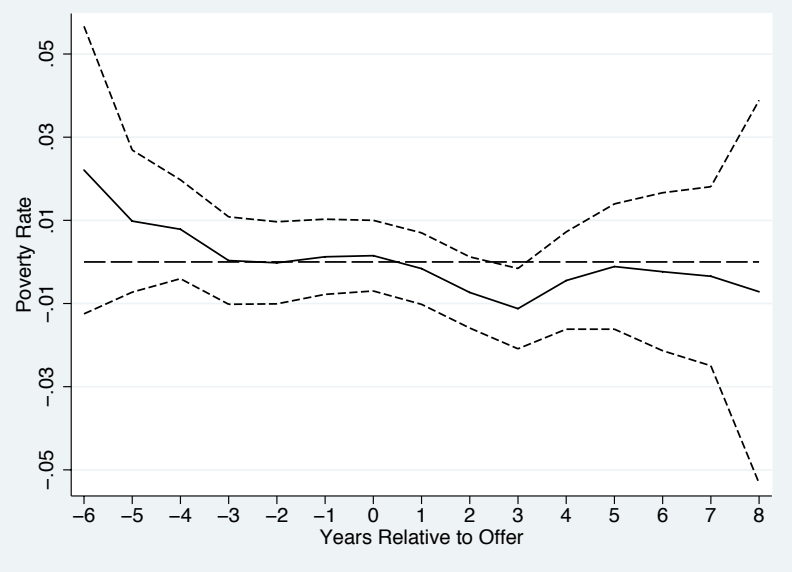

(b) Neighborhood Poverty Rate

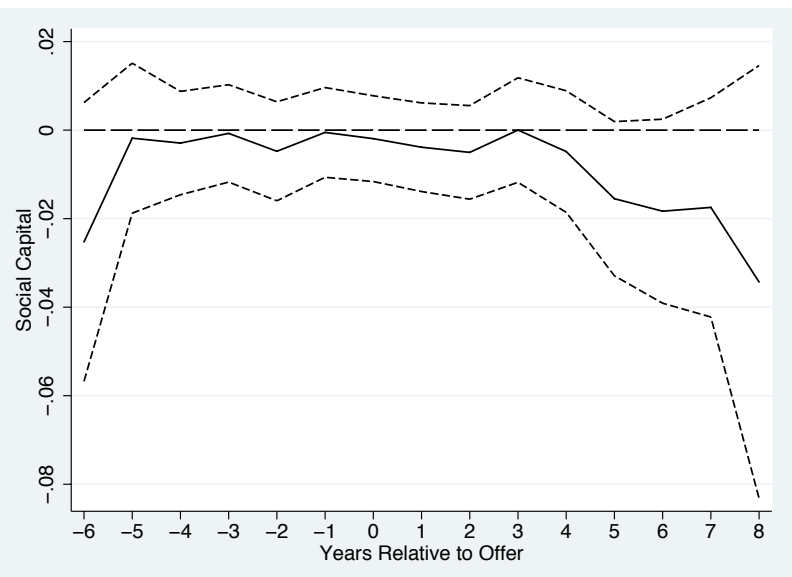

(d) Social Capital Score



(f) Violent Crime Arrest Rate

Notes: Dotted lines represent the 95 percent confidence interval. Solid lines represent the point estimate. Estimates come from equation (4) in the text. Year zero is defined as the first full year after an offer, measured at the quarter level, and including the quarter of the offer. Sample includes all working-age, able-bodied CHAC applicants who were living in private housing at baseline. 


\section{Appendix A: \\ Program Rules for Housing Vouchers, TANF and Food Stamps}

Housing vouchers

Eligibility for the housing voucher program is related to the local median household income. Specifically, for a family of four, eligibility is limited to 50 percent of the local median income for all families. (By way of comparison, the federal poverty line is usually around 30 percent of the local median). Some families with incomes up to 80 percent of the local median income may be eligible, including those who are in Section 8 project-based units when the private-market landlord opts out of the government program, as well as those who are displaced as a result of HUD's Hope VI public housing demolition program. The eligibility limits for families of different sizes equal the following percentages of the four-person limit (taken from Olsen, 2003, p. 379):

Table A1: Housing voucher eligibility by family size (relative to four-person limit)

$\begin{array}{cc}\text { Family Size } & \text { Percentage Adjustment } \\ 1 & 70 \% \\ 2 & 80 \% \\ 3 & 90 \% \\ 4 & 100 \% \\ 5 & 108 \% \\ 6 & 116 \% \\ 7 & 124 \% \\ 8 & 132 \%\end{array}$

The maximum subsidy available to families is governed by the Fair Market Rent (FMR), which was equal to the $45^{\text {th }}$ percentile of the local rent distribution for a unit of a given size up through 1995. It was then lowered to the $40^{\text {th }}$ percentile in 1995, and beginning in 2001 specific metropolitan areas, including Chicago, were allowed to set the FMR equal to the $50^{\text {th }}$ percentile. In Chicago, the FMR is defined for the entire Metropolitan Statistical Area (MSA). The voucher subsidy is equal to (taken from HUD, 2002):

Subsidy $=[\mathrm{FMR}-\mathrm{S}]$

$\mathrm{S} \quad=$ Family's monthly rent payment

$=\max \left\{.3 \times \mathrm{Y}_{\mathrm{ah}}, .3 \times \mathrm{GR}\right\}$

$\mathrm{Y}_{\mathrm{ah}} \quad=$ Adjusted Income under housing program rules

$=$ Earnings + TANF $-(\$ 480 \times$ Children $)-(\$ 400 \times$ Disabled $)-$ Child Care Expenses [Unreimbursed Medical Care Expenses Over 3\% of Annual Income] - [Unreimbursed Attendant Care or Auxiliary Apparatus Expenses to Disabled Family Members That Support Work by Other Family Members, Over 3\% of Annual Income]

GR $=$ Gross Rent 
Note that TANF benefits are counted as part of income for the purposes of calculating program eligibility and the family's rent contribution, while the value of both Food Stamp and Medicaid benefits is not. Income from the EITC is also not counted towards income under the voucher program rules, nor is any earnings by children under age 18 or payments received for the care of foster children.

Note also that families offered housing vouchers have a limited time to lease up a unit from when they are offered the voucher (usually 3 to 6 months; while they may request an extension, there is still ultimately a finite search period). Families can also only use vouchers in private-market units that meet HUD's minimum quality standards. Landlords may prefer tenants paying with cash over those with vouchers because of these quality standards and other HUD paperwork involved with the program. The combination of these three factors helps explain why many families who are already living in private-market housing fail to use a voucher when it is offered to them - they fail to successfully find and lease up a new unit that meets the quality standard within the specified time period.

Unlike other social programs, once an individual qualifies for a housing voucher, the person is not removed from the program if his or her income exceeds the eligibility limit. However, since they are required to pay 30 percent of their income toward their rent, the actual amount of their subsidy will decrease. Essentially, this means that there is no "notch" in the budget constraint with housing vouchers - there is simply a smooth phase-out. Since the average earnings of families in our CHAC applicant sample is so low - $\$ 14,000$ at baseline - and the phase-out range is $\$ 43,000$, most families probably expect to receive some sort of subsidy for a very extended period if time if they are offered a voucher.

\section{Temporary Assistance for Needy Families (TANF)}

The TANF program in Illinois replaced AFDC on July 1, 1997, at almost exactly the same time as the CHAC housing voucher program. Thus all of the post-lottery data analyzed in this paper were generated in a social policy environment governed by TANF rules.

TANF provides cash assistance to: (1) families with children but without any employed members, and with assets low enough to be eligible; (2) families with children and at least one employed member, but with incomes and assets low enough to be eligible; and (3) children whose parents have incomes and assets low enough to be eligible for TANF, but are not because they are not U.S. citizens or eligible non-citizens, or receive some other form of cash assistance such as SSI or SSA disability. Asset limits under the TANF program are equal to $\$ 2,000$ for one-person TANF filing units, $\$ 3,000$ for 2-person filing units, and increase by $\$ 50$ for each additional person in the filing unit. The TANF benefit is essentially equal to:

TANF benefit $=\mathrm{P}-.3 \times \mathrm{Y}_{\mathrm{at}}$

$\mathrm{Y}_{\mathrm{at}} \quad=$ Adjusted income under TANF program rules 


\section{$=$ Earnings - Workers Deduction $(\$ 90)-{\text { Child } \text { Care }^{1}}^{1}$}

Note that the maximum payment, $\mathrm{P}$, varies by family size and the type of TANF case. Under the TANF program in Illinois, income in these formulas does not include benefits from housing vouchers, Food Stamps, the EITC, or government programs such as VISTA or the Job Corps, nor does it include earnings through college work-study or those earned by dependent children. If families reduce their work without prior permission from the Illinois Department of Human Services or they failed to report their earnings (and then those earnings are discovered), they are taxed at a 100 percent rate.

\section{Food Stamps (FS)}

Currie (2003) notes that FS benefits are reduced by 30 cents for each dollar of either earned or unearned income (including income from cash transfer programs).

$$
\begin{aligned}
\mathrm{Y}_{\mathrm{g}} & =\text { Gross Income } \\
& =\text { Earnings }+\mathrm{TANF} \\
\mathrm{Y}_{\mathrm{n}} & =\text { Net Income } \\
& =\mathrm{Y}_{\mathrm{g}}-\text { Standard Deduction }(\$ 134)-.2 \times \text { Earnings }- \text { Child Care }^{2}-\min \{\$ 250, \mathrm{R}\} \\
\mathrm{R} & =\mathrm{Rent}-.5 \times\left[\mathrm{Y}_{\mathrm{g}}-\text { Standard Deduction }(\$ 134)-.2 \times \text { Earnings }- \text { Child Care }\right]
\end{aligned}
$$

Note that gross income under the Food Stamp program includes the household's total cash income, including earnings and TANF benefits, minus some excluded sources (such as earnings from dependent children and payments from the EITC).

\footnotetext{
1 Where applicable, subject to a maximum deduction in eligible cases. See IDHS Program Manual, 08-01-02-d, http://www.dhs.state.il.us/page.aspx?item=15234

2 Currie (2003), p. 207 reports that the dependent care expenses for those in work activities or training equal up to $\$ 175$ per month per child (or \$200 for children under age 2).
} 


\section{Appendix B: \\ Procedure for Identifying Other CHAC Household Members}

The CHAC application forms ask household heads for information on the total number of male and female adults, and male and female children, living within the home, but only ask for individual identifying information (name, date of birth, and social security) for the head and his or her spouse (if applicable). Only when families with sufficiently good lottery numbers were offered housing vouchers by $\mathrm{CHAC}$ did the organization ask household heads to provide individual identifying information on all household members.

In order to preserve the strength of our research design - random assignment of households to the voucher waiting list - we must identify household members for all families across the entire CHAC waiting list using the same method. To do this, we subcontracted with Chapin Hall at the University of Chicago to match the individual identifying information available for all CHAC applicants and their spouses to administrative data on social program participation from the Illinois Department of Human Services (IDHS). The essence of our approach is to identify any other individuals who were listed as a member of the CHAC applicant's household (based on the IDHS data) during the pre-CHAC lottery period. As noted in the text, the imputation strategy we follow means that our estimates involving other household members will be representative of the subset of CHAC applicants who appear on the IDHS files prior to July 1997, because they themselves or someone in their household was receiving AFDC/TANF, food stamps or Medicaid during this period. However, because approximately 94 percent of the 82,607 CHAC applicants appear on the IDHS files prior to the lottery, our estimates reflect the vast majority of housing applicants. Roughly XX percent of the main sample for the analysis presented in this paper (i.e., working-age, able-bodied adults living in private housing at baseline) appear in the IDHS files prior to the voucher lottery.

This appendix summarizes the procedures we use to impute the identity of other members of the households that applied to CHAC for vouchers, and then discuss how well these procedures appear to work.

\section{B1. Household Member Imputation Procedure}

Chapin Hall was able to match around 94 percent of CHAC applicant households to the IDHS client data base (CDB) using probabilistic matching techniques that use a combination of name (converted to Soundex), dates of birth, and Social Security numbers. For each CHAC applicant (or spouse) who matched to the IDHS CDB, Chapin Hall identified their spell of social program participation that was closest in time prior to the date of the CHAC lottery (7/1/97), which we call the "target case." We then identified the other members of the CHAC applicant household through the following multiple-step process:

1. Identify everyone who was in the CHAC applicant's (or spouse's) target case.

2. Then determine the target case for everyone identified in step (1). Note that some members of the CHAC applicant's target case could have a different target case if, for example, the daughter of a welfare recipient left her mother's household before the time 
of the CHAC lottery and started her own household and then also received welfare benefits on her own for this new household.

3. For individuals whose target case is the same as that of the CHAC applicant, we count these people as members of the CHAC applicant's household.

4. For individuals whose target case is different from that of the CHAC applicant, we count these people as members of the CHAC applicant's household (as well as anyone else listed as part of the household in this target case) only if the address of this other household member's target case is equal to the address of the CHAC applicant's target case. This scenario could occur if, for example, the daughter of a CHAC applicant has started her own welfare spell but continues to live with her mother.

Note that our procedure counts everyone who we believe was living in the CHAC applicant's household at the time of the voucher lottery as being part of the study sample. It is possible that some people living in these baseline households might start their own households during the post-lottery period, particularly if the CHAC applicant receives a voucher. Under our definition everyone in the baseline household at the time of the voucher application is counted as "treated," even household members who do not move, since they still experience some "treatment" from a reduction in crowding within the housing unit.

\section{B2. How Well Does This Imputation Procedure Work?}

Our process for identifying household members is necessarily imperfect and will introduce some measurement error into our measures of household composition. To explore the extent of measurement error, we examine the subset of CHAC applicant households who matched to the IDHS files pre-lottery. Starting with this set of 77,666 households, we drop roughly 2,400 households with missing data on gender for any household member and 84 households that report more than 10 household members on the $\mathrm{CHAC}$ application forms (which we believe is most likely due to a data entry errors). Our final sample thus includes 75,145 households. Note that including cases with missing gender or large number of household members yields nearly identical results to those reported below.

Our imputation procedure and the CHAC baseline applications identify the exact same number of total household members in 47.4 percent of cases (the CHAC applications reported more in 38.7 percent of cases); the same number of adult females in 70.8 percent of cases (the CHAC applications reported more in 6.9 percent of cases); the same number of male adults in 71.9 percent of cases (the CHAC applications reported more adult males in 19.4 percent of cases); and the same number of children for over half (56.5 percent) of applications (the CHAC forms reported more children in 36.7 percent of cases). Table B1 presents a more thorough breakdown of whether our IDHS estimation procedure and the CHAC applications are identifying the same number of household members. 
Table B1: To what extent does the IDHS estimation procedure over or underestimate household size? $(\mathrm{N}=75,145)$

Fraction of the cases in which:

\begin{tabular}{|c|c|c|c|c|c|}
\hline & CHAC and & $\mathrm{CHAC}$ & $\begin{array}{l}\text { ion of the cases } i \\
\text { r than IDHS by: }\end{array}$ & $\begin{array}{l}\text { which: } \\
\text { IDHS g1 }\end{array}$ & than CHAC by: \\
\hline & IDHS equal & One & More than one & One & More than one \\
\hline $\begin{array}{l}\text { Number of } \\
\text { Female Adults }\end{array}$ & 0.71 & 0.06 & 0.01 & 0.20 & 0.03 \\
\hline Number of Male & & & & & \\
\hline $\begin{array}{l}\text { Adults } \\
\text { Number of }\end{array}$ & 0.72 & 0.17 & 0.02 & 0.08 & 0.01 \\
\hline $\begin{array}{l}\text { Female Children } \\
\text { Number of Male }\end{array}$ & 0.71 & 0.16 & 0.06 & 0.05 & 0.02 \\
\hline $\begin{array}{l}\text { Children } \\
\text { Number of Total }\end{array}$ & 0.67 & 0.19 & 0.08 & 0.04 & 0.01 \\
\hline $\begin{array}{l}\text { Adults } \\
\text { Number of Total }\end{array}$ & 0.70 & 0.10 & 0.03 & 0.13 & 0.04 \\
\hline $\begin{array}{l}\text { Children } \\
\text { Total Household }\end{array}$ & 0.57 & 0.21 & 0.15 & 0.04 & 0.03 \\
\hline Size & 0.48 & 0.21 & 0.17 & 0.08 & 0.06 \\
\hline
\end{tabular}

Table B2 presents comparisons for the average household size and compositions implied by the CHAC applications and our imputation procedure.

Table B2: Comparisons of average household size as reported on CHAC application forms versus the IDHS estimation procedure $(\mathrm{N}=75,145)$

$\begin{array}{lcc} & \text { CHAC Applications } & \text { IDHS Estimates } \\ \begin{array}{l}\text { Number of } \\ \text { Female Adults }\end{array} & 0.86 & 1.04 \\ \begin{array}{l}\text { Number of Male } \\ \text { Adults }\end{array} & 0.45 & 0.33 \\ \begin{array}{l}\text { Number of } \\ \text { Female Children }\end{array} & 0.79 & 0.59 \\ \begin{array}{l}\text { Number of Male } \\ \text { Children }\end{array} & 0.92 & 0.60 \\ \begin{array}{l}\text { Number of Total } \\ \text { Adults }\end{array} & 1.31 & 1.37 \\ \begin{array}{l}\text { Number of Total } \\ \text { Children }\end{array} & 1.72 & 1.19 \\ \begin{array}{l}\text { Total Household } \\ \text { Size }\end{array} & 3.03 & 2.56\end{array}$

One reason the IDHS data may understate household size is that some welfare target cases may end before 7/1/97, and so we might miss household members who enter between the end of that target spell and the time of the CHAC voucher lottery. To test this hypothesis, we replicated the above tables using only those households where the household head's target case 
was active at the time of the CHAC voucher application period (that is, the household head's most recent social program spell prior to $7 / 1 / 97$ was still active on that date), and find comparable results.

The key question for identification in our study is whether any error in the identification of household members is systematically related to a family's position in the CHAC housingvoucher lottery. Given the procedure we used to impute household members (namely the fact that it relies entirely on pre-lottery information), there should be no such relationship. To address this question empirically, we create the following variables to characterize disagreements between the CHAC applications and our IDHS estimation procedure for each household in our analytic sample: a dummy variable equal to 1 if the $\mathrm{CHAC}$ application reports more people in the household than does our IDHS estimation procedure, and equal to 0 otherwise; a dummy indicator equal to 1 if the IDHS data report more people in the household than does the CHAC data, and equal to 0 otherwise; a variable equal to the difference between the total number of household members reported on the CHAC application and the total number of household members suggested by our IDHS estimates; and similar variables for specific sub-groups of household members (female adults, male adults, total adults, female children, male children and total children).

First, we regress each of these outcome measures against each household's actual lottery number. Out of the 21 total regressions that we estimate, only one yields a coefficient on the household lottery variable that is statistically significant at the 5 percent level, about what we would expect by chance alone. (The one significant coefficient suggests that households with higher lottery numbers are somewhat more likely to have more male adults reported by our IDHS estimation procedure than on the CHAC baseline application, with $\mathrm{p}=.047$, although the measure for the actual difference in the number of male adults between the two datasets, as opposed to a dummy variable indicating that there is a discrepancy, is not significant). Of course these 21 regression coefficients for comparing measures from the IDHS and CHAC applications are not truly independent; if we focus on the four independent measures of household size (actual difference between the two data sources for female adults, male adults, female children, male children), none of these are statistically significant.

The regressions reported above look for some linear relationship between voucher wait list position and measurement error in our IDHS household identification procedure. But in principle there could be some non-linear relationship between wait list position and this measurement error, if for example families who are offered vouchers immediately are more likely to be captured by the IDHS records for some reason. To explore this possibility, we create a set of indicator variables that divide families up into groups of 5,000 based on each household's CHAC lottery number, and regress each of the outcome measures described above against these lottery number indicators. Of the 315 total regression coefficients that we generate, only five are statistically significant at the 5 percent level, about what we would expect based on chance alone. If we focus only on the raw difference in household members between the two data sources for the four independent groups (female adults, male adults, female children, male children), only one of these sixty regression coefficients is statistically significant. 


\section{B3. Who gets missed by our household member identification procedure?}

While it is reassuring that there is no systematic relationship between CHAC lottery numbers and measurement error in household composition, the question of who gets missed by our IDHS estimation approach to household composition is still of some interest to our study.

We cannot directly determine who is included in the household count on the CHAC application forms because the former includes total counts of other household members but not individual identifying information. We instead take advantage of the fact that households who lease up with a voucher are required to fill out what are called HUD 50058 forms, which capture individual identifying information for everyone in the household that is leasing up. So we can try to learn more about who is missed by our IDHS household identification procedure by comparing the results of our IDHS procedure with who is listed on the HUD 50058 forms, at least for those households who lease up.

There are several limitations to this approach. First, those families who lease-up are different in some observable and likely unobservable ways from those families who were offered a voucher but do not lease up (see Table II of the paper). Second, household composition could change between the time when a family applies to CHAC and when they are actually offered a voucher and lease up (members could in principle be either lost or added in the interim). For this reason, we focus this analysis on those households who were offered a voucher by the end of 1998 (within the first 16 months following the start of the program) and who lease up. Tables B3 and B4 indicate that the patterns documented in Tables B1 and B2 are also apparent in this subsample. ${ }^{3}$

Table B3: To what extent does the IDHS estimation procedure over or underestimate household size for those households who were offered a voucher by 1998 and leased up? $(\mathrm{N}=2,164)$

Number of CHAC and CHAC greater than IDHS by: IDHS greater than CHAC by: IDHS equal One More than one One More than one

Female Adults

0.70

0.06

0.01

0.20

0.02

Number of Male

Adults

0.72

0.18

0.02

0.07

0.01

Number of

Female Children

0.71

0.16

0.05

0.05

0.02

Number of Male

Children

0.67

0.19

0.08

0.04

0.02

Number of Total

Adults

0.73

0.10

0.02

0.12

0.03

Number of Total

Children

0.57

0.21

0.15

0.04

0.03

3 Note that the sample of 2,164 households included in this analysis meet the following sample criteria: (1) the household head (or spouse) appeared in the IDHS files prior to the voucher lottery; (1) the household was offered a voucher by 1998; (3) the household utilized the voucher and leased an apartment; (4) the household reported at most 10 total household members on the voucher application form. 
Total Household

$\begin{array}{llllll}\text { Size } & 0.49 & 0.21 & 0.17 & 0.07 & 0.05\end{array}$

Table B4: Comparisons of average household size as reported on CHAC application forms versus IDHS estimation procedure for those households who were offered a voucher by 1998 and leased up? $(\mathrm{N}=2,164)$

\begin{tabular}{|c|c|c|}
\hline & CHAC Applications & IDHS Estimates \\
\hline $\begin{array}{l}\text { Number of } \\
\text { Female Adults }\end{array}$ & 0.86 & 1.03 \\
\hline $\begin{array}{l}\text { Number of Male } \\
\text { Adults }\end{array}$ & 0.42 & 0.27 \\
\hline $\begin{array}{l}\text { Number of } \\
\text { Female Children }\end{array}$ & 0.81 & 0.64 \\
\hline $\begin{array}{l}\text { Number of Male } \\
\text { Children }\end{array}$ & 0.98 & 0.66 \\
\hline $\begin{array}{l}\text { Number of Total } \\
\text { Adults }\end{array}$ & 1.28 & 1.30 \\
\hline $\begin{array}{l}\text { Number of Total } \\
\text { Children }\end{array}$ & 1.79 & 1.30 \\
\hline $\begin{array}{l}\text { Total Household } \\
\text { Size }\end{array}$ & 3.06 & 2.60 \\
\hline
\end{tabular}

Our next step is to try to figure out who exactly is in the 50058 data but not identified by our IDHS procedure, and who is identified by our IDHS procedure but do not show up in the HUD 50058 forms. We do this by attempting to match specific individuals through some combination of name, DOB and SSN. We restrict this sample to non-household heads because the goal of this analysis is to compare who shows up in the 50058 data to who is identified using our IDHS procedure, and all household heads will show up in the 50058 data by definition. As above, we limit this analysis to the set of 2,164 households who were offered vouchers in 1997 or 1998 and who utilized these vouchers to lease up.

Comparing the 50058 records to either the IDHS or CHAC application records for this set of households, we find the 50058 records contain a larger number of people. Specifically, the average number of children (non-head adults) in the 50058 records is $2.15(0.29)$ compared with $1.79(0.28)$ in the CHAC application files and $1.30(0.30)$ in the IDHS records. This suggests that individuals may have "joined" successful CHAC applicants in starting a new household, which is consistent with evidence that voucher receipt is often accompanied by changes in household composition (see, for example, Gubits et al., 2006). It may also be the case that families have a greater incentive to accurately and fully account for all household members on 50058 forms. Individuals had no incentive to accurately report household size or composition on the CHAC application form. And we know that the IDHS records may not contain information on individuals who do count toward the benefits calculation for the family, as in the case of other adults and AFDC/TANF benefits. 
Table B5 shows that roughly 77 percent of the 3,417 non-household heads who appear in our IDHS sample show up in the 50058 data. However, the match rates for young children in our IDHS sample are much higher - approximately 90 percent for those children under the age of 11 . Among children age 11-15 that we identify in our IDHS sample, 83 percent also appear in the 50058 records, while the match rate for 16-17 year olds are noticeably lower (i.e., 70 percent). Interestingly, very few of the adult family members we identify in the IDHS files appear in the 50058 data. This pattern is consistent with a situation in which young children are very likely to accompany their parent or guardian to a new residence, but that the receipt of a housing voucher allows adults who had previously been living together to form their own households.

\section{Table B5: The fraction of non-household heads who appear in IDHS records $(n=3,417)$ that also matched to 50058 records, separately by age}

Fraction of the total
$\begin{gathered}\text { Fraction of individuals } \\ \text { sample of } 3,417\end{gathered}$
individuals

Age as of $7 / 1 / 97$

All ages

1.00

(2)

$0-3$

0.20

0.77

4-6

7-10

0.19

0.91

11-15

0.21

0.88

16-17

0.18

0.90

$18-25$

0.05

0.83

$25-45$

0.07

0.71

0.07

0.30

45-65

0.03

0.20

65 or older

0.01

0.32

0.35

\section{B4. Summary}

Because the CHAC application forms list the total number of adults and children in the home but do not provide individual identifying information about household members other than the household head and his or her spouse (if applicable), we use IDHS data on pre-CHAC-lottery social program spells to identify other household members using the procedure described above. Our IDHS procedure suggests household sizes that are about one-half child smaller than what is suggested by the CHAC application files. However, a comparison of the individuals who appear in our IDHS data and those who later appear on official HUD 50058 forms among those families who utilized a housing voucher suggests our IDHS imputation procedure correctly identifies nearly all of the young children (below the age of 15) in a household and a fairly high (70 percent) fraction of older children. On the other hand, it appears that our IDHS estimation may not reliably identify other adults associated with the household. Finally, and quite importantly, the analysis reported here confirms that the measurement error in identifying household members is unrelated to the randomly assigned $\mathrm{CHAC}$ voucher wait list position. 


\section{Appendix C: \\ Data Appendix}

Baseline information on the 82,607 adults and nearly 8,700 spouses that applied to CHAC for a housing voucher in 1997 comes from the lottery application forms. These files include information on address, lottery number and household demographics such as the number and gender of other children and adults in the household, as well as identifying information (names, date of birth, and social security number) for the household heads and spouses. We impute certain demographic variables that are either incomplete or not included on the application forms using information from the Illinois Department of Human Services (IDHS) Client Data Base (CDB). For example, household head gender is not included on the CHAC application form, so we use gender from the CDB. For household heads who do not appear in the CDB, we impute gender by comparing their first name with lists of names of known gender using four data sources: Census data, Social Security Administration data, two websites with lists of names; and finally using a gender-assigning algorithm. For spouses with missing gender, we assign them the opposite gender of the household head.

Similarly, to determine race we start with the CDB race variable and then impute missing values using the less complete lottery application information. For those observations that are missing, we check to see whether the "multiple races" box is checked on the CHAC application. To determine the coding of these multiple races, we create an empirical link by looking at those individuals with multiple races on the CHAC application forms and who also have race information in the CDB. For each combination of multiple races we choose the modal race that is indicated by the CDB. For example, if those who are listed as both white and Hispanic on the CHAC forms are listed most often as Hispanic in the CDB, then we assume that all people marked both white and Hispanic in the CHAC forms are Hispanic.

To create and clean our age variables, we use information from both the CHAC application forms and the IDHS client database. The age variables we create indicate age during 1997 when the CHAC lottery application takes place. They include two household invariant variables - household head age and spouse age - and one person invariant age variable for the person in question. For the household heads, if the CHAC age is missing but we have CDB age, then we use CDB age. If he or she indicates age less than 16 on the application form and we have no $\mathrm{CDB}$ information, then we set age equal to missing. If the CHAC age is less than 18 or greater than 70, and the difference between that age and the CDB age is greater than one, then we use the CDB age. For spouse age, we use date of birth information if available and when missing we use CDB age as long as it is a reasonable value (ie, not less than 16). For kids and other household members we first check for members age 0 to 18 that are a household head or spouse somewhere else in the sample (e.g., a 17 year who applied as a head and is also the child of a parent who applied separately as a head). For those that we find, we make sure their age is consistently reported across observations. There a small number of observations that have age greater than 100 and we set these equal to missing.

There are several seemingly infeasible outliers in the CHAC information on household composition. We take the following steps to clean this information: for number of male children 
and female children we set values ranging from 20 to 29 equal to 2 , and values from 10 to 19 equal to 1. Similarly for number of adult females and adult males, we set values of 10,11 and one instance of 81 , all equal to 1 . We set negative values equal to 0 . When there are zero adults listed, we impute one adult, male or female based on household head gender. We then create total household, total adult, and total child categories by summing the cleaned household composition variables. We confirm that these cleanings have no impact on our randomization checks or any other results.

Data on voucher utilization comes from HUD 50058 records, which families must complete at least once a year to verify eligibility and also when they exit or enter housing programs or if household composition or income changes. These HUD 50058 forms provide complete longitudinal information on housing assistance administered by CHAC (i.e., all tenantbased rental assistance such as Section 8 vouchers and certificates, but excluding public housing), including when the household started and stopped receiving assistance and the different addresses where the household's lived while on a Section 8 voucher. We merge the application data to $\mathrm{CHAC}$ files on voucher utilization using CHAC tenant identification numbers coupled with name, social security number and date of birth. We use a probabilistic match that is robust to misspellings, typos and other minor inconsistencies across data sets. These files also provide information on the type of apartment leased, and the number of members in the household.

To track residential locations for both the treatment and control groups we rely on passive tracking sources such as the National Change of Address (NCOA) registry and national credit bureau checks. Because of resource constraints, we tracked a random ten percent sub-sample of all CHAC applicants. We have confirmed that this subset matches the overall applicant pool on a variety of baseline characteristics, and that the impact estimates on labor supply for this 10 percent sub-sample are virtually identical to the impact estimates for the full sample. We are also able to (at least partially) verify the accuracy of the passive tracking techniques using the subset of families that received housing vouchers. In the vast majority of these cases, the location information obtained through passive tracking matches the information found in the administrative 50058 records. Using these addresses along with 2000 census data, we are able to characterize each household's residential neighborhood down to the block group level.

We determine whether a family was living in public housing or a project-based Section 8 housing at the time of the lottery by merging baseline addresses from the CHAC application files to lists of subsidized units maintained by the Chicago Housing Authority and HUD. We use baseline housing status because housing arrangements may be influenced by the outcome of the voucher lottery. This means the group identified as living in a housing project at baseline may include some families who are in private-market housing by the time they are actually offered a housing voucher by CHAC. This occurs in part because of the natural transition of families out of project-based housing units over time, and in part because the city of Chicago was demolishing thousands of units of public housing during the course of the 1990's (see Jacob 2004).

To measure labor market participation and earnings we have obtained quarterly earnings data from the Illinois unemployment insurance (UI) program, maintained by the Illinois 
Department of Employment Security (IDES). If an individual works at more than one employer in a given calendar quarter, we aggregate up earnings from all employers. People in our sample are counted as working in a given quarter if they report having any earnings at all in the UI data in a quarter. Household-level employment is defined as having anyone in the CHAC baseline household show any earnings in a given quarter. We set to missing those person-quarter observations where quarterly earnings are reported to be less than $\$ 5$ in nominal terms. We set equal to the $99^{\text {th }}$ percentile of the distribution those outlier observations greater than the $99^{\text {th }}$ percentile. Earnings figures are then converted into constant 2007 dollars.

We obtain our welfare information from the IDHS administrative data bases. They provide us with start and end dates of ACDF/TANF, Food Stamp and Medicaid spells for every household member of those households that we match to the CDB. From these start and end dates we then create for each of the welfare programs, a variable indicating the number of days during the current quarter a person was receiving assistance and separate binary indicators for whether the person received assistance during the current quarter, the first quarter of 1997, and second quarter of 1997 . We also create binary indicators for whether the household head received assistance of any type during the current quarter, the first quarter of 1997, and the second quarter of 1997.

Unless otherwise noted, the baseline covariates in all of our models include the following variables: binary indicators for black, Hispanic, white, other race, male, disabled, spouse present; a quartic in age interacted with the male indicator; continuous measures of the number of adults in the household, the number of children in the household, and the number of days after the opening of the waiting list that the family submitted an application; binary indicators based on self-reported information from the CHAC application form of whether the household head was willing to accept a certificate as well as voucher, currently receiving any earned income, currently receiving any SSI benefits, currently receiving AFDC/TANF; a series of measures drawn from Illinois administrative databases describing the household head's public assistance receipt and employment in the first and second quarter of 1997, including binary indicators for whether the household head worked, received TANF, received any public assistance (Medicaid, Food Stamps or TANF), and total earnings in the quarter; a series of 12 binary indicators of total prior arrests for different crimes (1,2,3+ prior arrests for a violent crime, property crime, drug crime or other crime); measures of the applicant's baseline neighborhood, all measured at the tract level, which include percent minority, percent black, poverty rate, collective efficacy, social capital, violent crime rate, property crime rate; the average earnings, employment and public assistance receipt of all household members in the second quarter of 1997; the average prior criminal history of all household members (i.e., 12 variables which are merely the household averages of the 12 binary prior crime variables above); the household's imputed fair market rent and baseline rent. 


\section{Appendix D: \\ Calculation of Baseline Rent, Income, and Effects of Housing Vouchers on Disposable Cash and Housing Consumption}

In order to understand the magnitude of the voucher "treatment dose," we would like to measure baseline income for CHAC applicants as well as their baseline rent contributions. Baseline rent and income are relevant because the maximum value of a voucher subsidy is a function of the family's income, while the amount of rent families are paying at baseline will determine how much of the voucher subsidy that families can take in the form of cash (by reducing their out-of-pocket spending on housing). Unfortunately, baseline rent and income are not reported on the CHAC application forms, and so we must estimate these values for families using the other sources of administrative data that we have available to us. Our estimation procedure will unavoidably add some error to our measures of baseline rent and income values. But since our estimation procedure for baseline rent and income relies entirely on pre-baseline administrative records, this measurement error should be orthogonal to each family's randomly assigned position on the $\mathrm{CHAC}$ voucher wait list.

\section{D1. Voucher subsidy effects on consumption of housing versus all other goods}

As discussed in detail in Appendix A, the maximum value of a family's housing voucher subsidy is equal to the HUD-defined Fair Market Rent (FMR) for a housing unit of the size to which the family is eligible, minus the family's rent payment, which under 1997 program rules was defined as the greater of .3 times net income (what most families pay), or in some cases, .1 times gross income (or the welfare rent payment - that is, the minimum amount of a family's welfare contribution towards rent).

The total subsidy value will equal Subsidy $=[\mathrm{FMR}-\mathrm{S}]=\mathrm{C}+\mathrm{H}$, where FMR is the Fair Market Rent (essentially the maximum rent of units that families can lease up with housing vouchers; see Appendix A), S is the family's required rent contribution under voucher program rules, $\mathrm{C}$ equals the amount of the subsidy value that the family can essentially take as cash (by reducing out-of-pocket spending on housing) and $\mathrm{H}$ is the increase in housing consumption from voucher receipt. $\mathrm{C}$ and $\mathrm{H}$ are calculated from three parameters: the FMR; baseline rent (BR); and baseline income (I), each of which we calculate from pre-lottery information for each CHAC family. Most families will be in the situation of being eligible for an apartment with FMR above their baseline rent, and will be spending far more on rent than 30 percent of their adjusted income (which is less than total income because the voucher program rules exclude certain sources of income, and allow families deductions for dependents and other reasons; see Appendix A). For these families, the amount of the voucher subsidy that they can take as cash is equal to the difference between their baseline out of pocket spending on rent (i.e., their baseline rent) less the amount they are required to spend on rent under the voucher program rules (30 percent of their adjusted income). The increase in housing consumption for a family that leases a unit with rent equal to the FMR is equal to the difference between the FMR and the family's baseline rent. Table D1 shows that the degree to which the family is able to take part of the voucher subsidy as cash versus increased housing consumption will be somewhat different for families with baseline rents above the FMR (second row) or required rent contributions under the voucher program rules that exceed their baseline rents (third row). 
Table D1: Effects of housing voucher for families already in private housing as function of baseline rent, income, and HUD-defined Fair Market Rent (FMR)

\begin{tabular}{|c|c|c|}
\hline $\begin{array}{c}\text { Baseline rent and } \\
\text { income }\end{array}$ & $\begin{array}{c}\text { Extra cash from } \\
\text { getting voucher }\end{array}$ & $\begin{array}{c}\text { Extra housing from } \\
\text { getting voucher }\end{array}$ \\
\hline FMR $>$ BR $>.3 * \mathrm{I}$ & $\mathrm{C}=(\mathrm{BR}-.3 * \mathrm{I})>0$ & $\mathrm{H}=($ FMR-BR $)>0$ \\
\hline $\mathrm{BR}>\mathrm{FMR}>.3 * \mathrm{I}$ & $\mathrm{C}=(\mathrm{FMR}-.3 * \mathrm{I})>0$ & $\mathrm{H}=(\mathrm{BR}-\mathrm{FMR})<0$ \\
\hline $\mathrm{FMR}>.3 * \mathrm{I}>\mathrm{BR}$ & $\mathrm{C}=0$ & $\mathrm{H}=(\mathrm{FMR}-.3 * \mathrm{I})$ \\
\hline $.3 * \mathrm{I}>\mathrm{FMR}$ & $\mathrm{C}=0$ & $\mathrm{H}=0$ \\
\hline
\end{tabular}

\section{D2. Estimating Fair Market Rents (FMR) for CHAC Applicants}

The FMR is a function of the number and gender composition of the adults and children in the household, the metropolitan area the family is living in, and the calendar year. CHAC applicants are required to report all the relevant information for household size and gender composition, and HUD publishes the FMR for a 2 bedroom unit for each local metro area for each year at www.huduser.org/datasets/fmr.html. We estimate the FMR for each CHAC family for 1997 using the baseline information on household composition that they report to CHAC on their voucher application to identify the largest apartment the family is entitled to, and then assign them the FMR for that size unit using the FMR reported by HUD for a 2 bedroom unit at the URL above, using the adjustment to the FMR for number of bedrooms to which the family is entitled described in Appendix A. The average 1997 FMR for CHAC applicant households headed by a working age, able-bodied adult in our dataset was around $\$ 1,000$ per month, or $\$ 12,000$ per year. $^{4}$

\section{D3. Estimating Baseline Incomes (I) for CHAC Applicants}

We begin by estimating total baseline income for households from all sources, without regard to the specific housing program rules about what does and does not count in the voucher program's "adjusted income" calculation for purposes of determining each household's voucher rent contribution. We sum all quarterly UI earnings reported for all household members for the four quarters prior to the CHAC application period (from 1996:Q3 through 1997:Q2). We know who is receiving TANF at baseline from both the CHAC application forms and IDHS administrative data. We do not know the exact amount of the TANF payments that families receive, so we use published TANF program rules for Illinois to estimate the TANF benefit

\footnotetext{
4 This FMR calculation uses the household size and gender composition that we estimate using the Illinois Department of Human Services (IDHS) data and estimation procedure described in Appendix B for households that ever show up in the IDHS data system; for those who do not show up in the IDHS system, we use the household composition and gender composition reported directly on the CHAC application forms. If we look at just the household composition among those who show up in the IDHS data, the FMR is equal to \$12,010, while if we use just the CHAC application data we have available for everyone (whether they show up in the IDHS data system or not), the FMR is equal to $\$ 12,600$. We prioritize the estimates for household composition obtained from the IDHS data using our Appendix B procedure because we can only calculate earnings and total income for people we can specifically identify through that IDHS procedure, and so the FMR calculation will be conceptually consistent with the income figures we estimate for each families.
} 
amounts for those whom our administrative data indicate are receiving TANF benefits. ${ }^{5}$ We also assume that every working household receives the EITC, and assign EITC income based on that program's benefit schedule for 1997 taken from Hotz and Scholz (2003). In principle one limitation with our procedure for estimating baseline income is that we do not have any data on family asset income (HUD voucher rules require families to count 2-3 percent of total net household assets as income), nor can we capture earnings from jobs that are not covered under the state's UI system. The omission of assets at least does not seem to matter much in practice when we examine 50058 data on voucher recipients in Chicago, average monthly asset income is on the order of $\$ 5$ per family. We estimate the average household income for CHAC applicants in the year before their voucher application to be $\$ 14,000$.

After calculating total family baseline income, we then tabulate the adjusted income value (the value for I in Table D1 above) that is used under housing voucher program rules to determine the family's rent contribution. We first subtract from total household income those sources that are not counted as income by the voucher program, namely EITC benefits as well as any earnings by household members under the age of 18 . We then also subtract allowable deductions that we can identify with the data available to us, namely the $\$ 480$ per child deduction under voucher program rules. Mean adjusted income for our sample of able-bodied, working-age CHAC adult applicants is $\$ 12,450$.

\section{D4. Estimating Baseline Rent for CHAC Applicants}

For our calculations we require a way of determining each CHAC applicant's baseline rent that we can apply consistently for all families across the entire voucher wait list. Unfortunately direct data on baseline rents is only available for families in our treatment group who were offered vouchers by CHAC, and then use their voucher to lease up in their same baseline apartment. The HUD 50058 forms that these families will be required to fill out as a condition of their voucher receipt will include complete information on their unit's rent.

To estimate baseline rents for our entire sample of CHAC applicants (treatment and control families), we use data from a special tabulation conducted for us by the Census Bureau using 2000 Census data for Chicago. We basically assign each CHAC applicant the average rent paid by households with similar basic demographic characteristics living in the CHAC applicant's same baseline census tract. We define household "types" or categories on the basis of the census tract of residence, race of the household head, number of adults in the home, and number of children in the home. The Census Bureau suppresses rent figures in cases where there are too few households of a given type in a given census tract. In these cases, we assign CHAC applicants the average rent for households with the same number of adults and children in the same census tract (regardless of race). In cases where the relevant rent figures for a given household type in a tract are also suppressed by Census confidentiality requirements, we assign the average rent from households in the same tract with the same number of children (ignoring race and number of adults). ${ }^{6}$

\footnotetext{
5 Program rules are taken from Lewis et al. (2000). The maximum welfare benefit is defined by family size and is basically equal to the maximum benefit minus one third of earned income by adults in the home. 6 Around 20 percent of our CHAC sample are assigned baseline rents for families of the same race, number of adults, and number of children in the same tract; around 75 percent of the CHAC sample are assigned rents based on
} 
A final complication in estimating baseline rents for CHAC applicants from the Census 2000 special tabulation is that we are interested in rents paid by families living in private-market housing, yet the 2000 Census questionnaire does not ask families whether they are living in public- or private-market housing. It is not clear what a family living in public housing would actually answer to a Census question about unit rent; would they, or should they, report their own out-of-pocket rent contribution, equal to 30 percent of adjusted income just as in the housing voucher program? Or would a family in public housing instead report some guess about the true market-equivalent "rent" for their public housing unit? (How a family would even begin to make such an assessment if they tried is not clear). We try to deal with this problem by estimating baseline rents under three different procedures: (a) using the mean rent reported by families in the 2000 Census, with no adjustments; (b) using median rent; (c) using an adjusted mean rent, where the adjustment assumes a truncated normal distribution for rents and truncates the rent distribution at the minimum rent cutoff used by HUD in their own calculations of the FMR (to weed out what HUD believes are likely to believe either public housing rents reported in the Census, or sub-standard private-market units). ${ }^{7}$ The results under each of these approaches are quite similar. We have also asked the Census Research Data Center at the University of Michigan to do some tabulations with restricted-use individual-level Census data excluding households with rents below the cutoff HUD uses; those mean rent figures across family types and tracts are generally similar to what the Census has estimated for us without any adjustment for low rents. The average baseline rent in our sample is estimated to be on the order of $\$ 680$ per month, or $\$ 8,160$ per year.

\section{D5. Summary of Results}

We estimate baseline total household income for the average able-bodied working-age adult CHAC applicant to be $\$ 14,000$. We estimate average baseline rent to equal $\$ 8,160$ per year, while the average FMR is equal to $\$ 12,000$. These calculations imply an average maximum voucher subsidy value (cost to the government) of \$8,265. Since Reeder (1985) estimates the ratio of benefit to the recipient to cost to the government for vouchers to be around .83 , this implies an average equivalent variation for a voucher on the order of $\$ 6,860$. Our calculations also imply that on average, the extra cash a family can take out of a voucher (C) will be around $(\mathrm{BR}-.3 * \mathrm{I})=(\$ 8,160-\$ 3,735)=\$ 4,425$ per month, while the family will increase their housing consumption $(\mathrm{H})$ by $(\mathrm{FMR}-\mathrm{BR})=\$ 12,000-\$ 8,160=\$ 3,840$. Put differently, the fact that families spend such a large amount of their baseline income on rent, and can then substantially reduce their spending on housing upon receipt of a voucher, means that the typical CHAC applicant is able to take more than half of the dollar value of the housing voucher subsidy in the form of cash.

households in the Census with the same number of adults and children in the same tract (pooling all races together); and the remaining 5 percent or so of CHAC applicants are assigned baseline rents of households with the same number of children in the same tract.

7 For the truncated mean adjustment we try this once using a common standard deviation calculated for households of all sizes citywide, and once trying to calculate tract-specific standard deviations for the rent distribution Here the data become quite limited given Census bureau data suppression at the tract level. In any case both procedures yield similar results. 


\section{Appendix References}

Angrist, Joshua A., Guido W. Imbens, and Donald B. Rubin (1996) "Identification of Causal

Effects Using Instrumental Variables," Journal of the American Statistical Association, 91: 444472

Currie, Janet (2003) "U.S. Food and Nutrition Programs" In Means-Tested Transfer Programs in the United States. Edited by Robert A. Moffitt. Chicago: University of Chicago Press. pp. 199290.

"Fact Sheet for HUD Assisted Residents, Rent Supplement, How Your Rent is Determined," HUD, Office of Housing, January 2002.

http://www.hud.gov/offices/hsg/mfh/gendocs/factsrentsup.pdf, 6/12/04

Gubits, Daniel B., Larry L. Orr, Gregory B. Mills, Michelle L. Wood, Bulbul Kaul, David A. Long and Judith D. Feins (2006) The Impact of Housing Choice Vouchers on Employment, Earnings and Mean-Tested Benefits. Cambridge, MA: Abt Associates draft report.

Jacob, Brian A. (2004) "Public Housing, Housing Vouchers, and Student Achievement: Evidence From Public Housing Demolitions in Chicago." American Economic Review. 94(1): 233-258.

Illinois Department of Human Services Policy Manual for Temporary Assistance to Needy Families, Deductions from Earned Income (Cash). 08-01-02-d: Adult/Teen/Child Care Disregard. http://www.dhs.state.il.us/rulesPolicy

Lewis, Dan A., Kristen L. Shook, Amy Bush Stevens, Paul Kleppner, James Lewis, and Stephanie Riger (2000) “Work, Welfare, and Well-Being: An Independent Look At Welfare Reform in Illinois." Illinois Family Study: Project Description and First Year Report. University Consortium of Welfare Reform

Olsen, Edgar O. (2003) "Housing Programs for Low-Income Households." In Means-Tested Transfer Programs in the United States. Edited by Robert A. Moffitt. Chicago: University of Chicago Press. pp. 365-442.

Reeder, William J. (1985) "The Benefits and Costs of the Section 8 Existing Housing Program." Journal of Public Economics. 26: 349-377. 


\section{Appendix Table I: Effects Of Housing Vouchers On All Household Members}

At least one member of $\mathrm{HH}$ employed

At least one member of $\mathrm{HH}$ on public assistance

At least one member of HH on TANF

Fraction of people in $\mathrm{HH}$ employed

Fraction of people in $\mathrm{HH}$ on public assistance

Fraction of people in $\mathrm{HH}$ on TANF

Total HH earnings

Total HH earnings per capita

Total HH earnings conditional on at least one working

Log total HH earnings conditional on at least one working

\begin{tabular}{|c|c|c|c|c|}
\hline $\mathrm{CM}$ & ITT & IV & CCM & $\begin{array}{l}\text { Number of } \\
\text { Households }\end{array}$ \\
\hline 0.665 & $\begin{array}{c}-0.011^{* *} \\
(0.004)\end{array}$ & $\begin{array}{c}-0.029 * * \\
(0.009)\end{array}$ & 0.680 & 42,358 \\
\hline 0.558 & $\begin{array}{l}0.023 * * \\
(0.004)\end{array}$ & $\begin{array}{c}0.058 * * \\
(0.009)\end{array}$ & 0.666 & 42,358 \\
\hline 0.182 & $\begin{array}{l}0.005^{* *} \\
(0.002)\end{array}$ & $\begin{array}{c}0.013 * * \\
(0.005)\end{array}$ & 0.150 & 42,358 \\
\hline 0.396 & $\begin{array}{c}-0.007 * * \\
(0.003)\end{array}$ & $\begin{array}{c}-0.019 * * \\
(0.006)\end{array}$ & 0.378 & 42,358 \\
\hline 0.464 & $\begin{array}{l}0.023 * * \\
(0.003)\end{array}$ & $\begin{array}{l}0.056 * * \\
(0.008)\end{array}$ & 0.554 & 42,358 \\
\hline 0.143 & $\begin{array}{l}0.004^{* *} \\
(0.002)\end{array}$ & $\begin{array}{c}0.012 * * \\
(0.004)\end{array}$ & 0.111 & 42,358 \\
\hline $4,390.22$ & $\begin{array}{c}-104.28 * * \\
(44.924)\end{array}$ & $\begin{array}{l}-269.02 * * \\
(108.852)\end{array}$ & $4,130.32$ & 42,358 \\
\hline $2,178.73$ & $\begin{array}{l}-84.67 * * \\
(21.228)\end{array}$ & $\begin{array}{c}-213.73^{* *} \\
(51.659)\end{array}$ & $1,912.70$ & 42,358 \\
\hline 6,599.27 & $\begin{array}{c}-53.26 \\
(51.773)\end{array}$ & $\begin{array}{c}-142.06 \\
(122.028)\end{array}$ & $6,072.94$ & 40,021 \\
\hline 8.407 & $\begin{array}{c}-0.024^{* *} \\
(0.008)\end{array}$ & $\begin{array}{c}-0.060 * * \\
(0.020)\end{array}$ & 8.352 & 40,021 \\
\hline
\end{tabular}

Notes: The unit of observation is person-year-quarter. The sample includes all working-age, able-bodied CHAC applicants who were living in private housing at baseline. CM = Control Mean. ITT = Intent-to-Treat. IV = Instrumental Variables. CCM = Control Complier Mean. See text for discussion of these estimates. Robust standard errors clustered at household level. ** = significant at 5\% level, * = significant at $10 \%$ level. All earnings are measured in 2007 dollars. 
Baseline

(1) Include households with lottery numbers

$18,103-35,000$

Scale by receipt of voucher through the 1997

(2) lottery (rather than simply receiving a voucher through any program)

Scale by actual voucher usage in each quarter

(3) (rather than defining voucher usage as all quarters post initial lease-up)

(4) Scale by actual usage of 1997 voucher (combination of changes in both rows 2 and 3 )

\begin{tabular}{|c|c|c|c|c|}
\hline \multirow[t]{2}{*}{$\begin{array}{l}\text { Number of } \\
\text { Households }\end{array}$} & \multicolumn{2}{|c|}{ Employed } & \multicolumn{2}{|c|}{$\begin{array}{c}\text { Receiving TANF, } \\
\text { Food Stamps, or } \\
\text { Medicaid } \\
\end{array}$} \\
\hline & IV & CCM & IV & CCM \\
\hline 42,358 & $\begin{array}{c}-0.036^{* *} \\
(0.009)\end{array}$ & 0.605 & $\begin{array}{c}0.067 * * \\
(0.009)\end{array}$ & 0.552 \\
\hline 53,135 & $\begin{array}{c}-0.038 * * \\
(0.009)\end{array}$ & 0.606 & $\begin{array}{c}0.069 * * \\
(0.008)\end{array}$ & 0.550 \\
\hline 42,358 & $\begin{array}{c}-0.034^{* *} \\
(0.008)\end{array}$ & 0.607 & $\begin{array}{c}0.062 * * \\
(0.008)\end{array}$ & 0.555 \\
\hline 42,358 & $\begin{array}{c}-0.044^{* *} \\
(0.011)\end{array}$ & 0.622 & $\begin{array}{c}0.081^{* *} \\
(0.010)\end{array}$ & 0.590 \\
\hline 42,358 & $\begin{array}{c}-0.042^{* *} \\
(0.010)\end{array}$ & 0.625 & $\begin{array}{c}0.076 * * \\
(0.010)\end{array}$ & 0.589 \\
\hline
\end{tabular}

Notes: The unit of observation is person-year-quarter. The sample includes all working-age, able-bodied CHAC

applicants who were living in private housing at baseline. $\mathrm{CM}=$ Control Mean. ITT = Intent-to-Treat. IV = Instrumental Variables. $\mathrm{CCM}=$ Control Complier Mean. See text for discussion of these estimates. Robust standard errors clustered at household level. $* *=$ significant at $5 \%$ level, * = significant at $10 \%$ level. 
Appendix Figure I: Control Group Outcomes Over Time

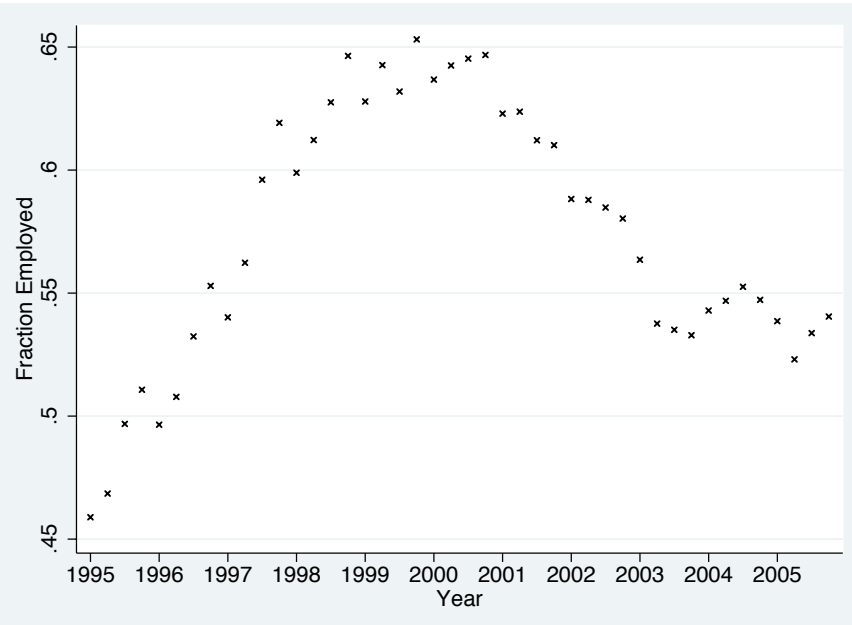

(a) HHH Employed

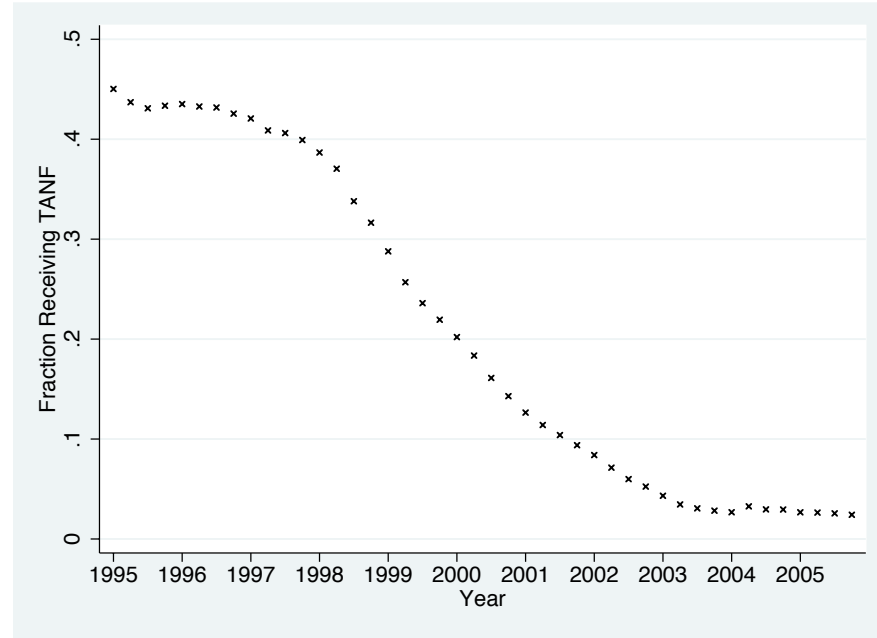

(c) HHH Receiving Cash Assistance

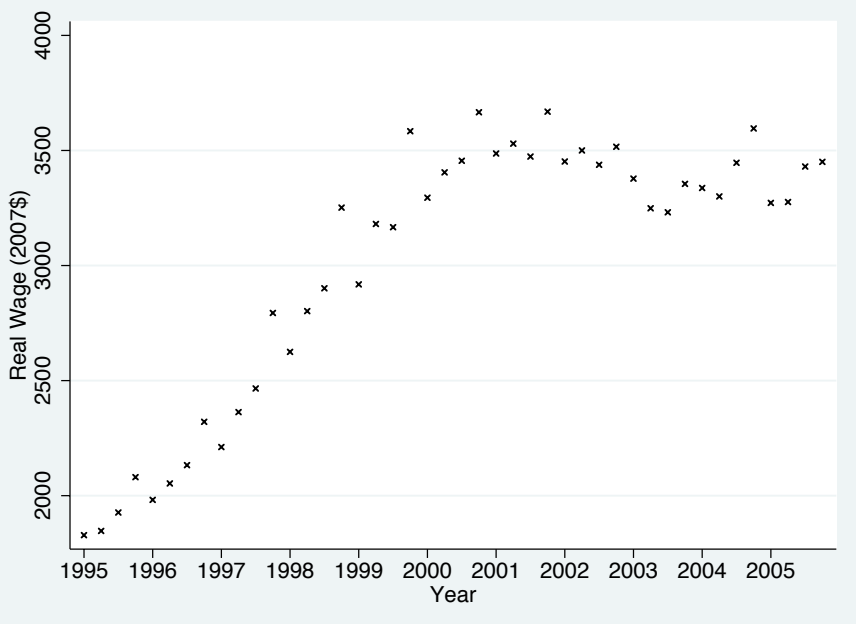

(b) HHH Real Earnings (2007\$)

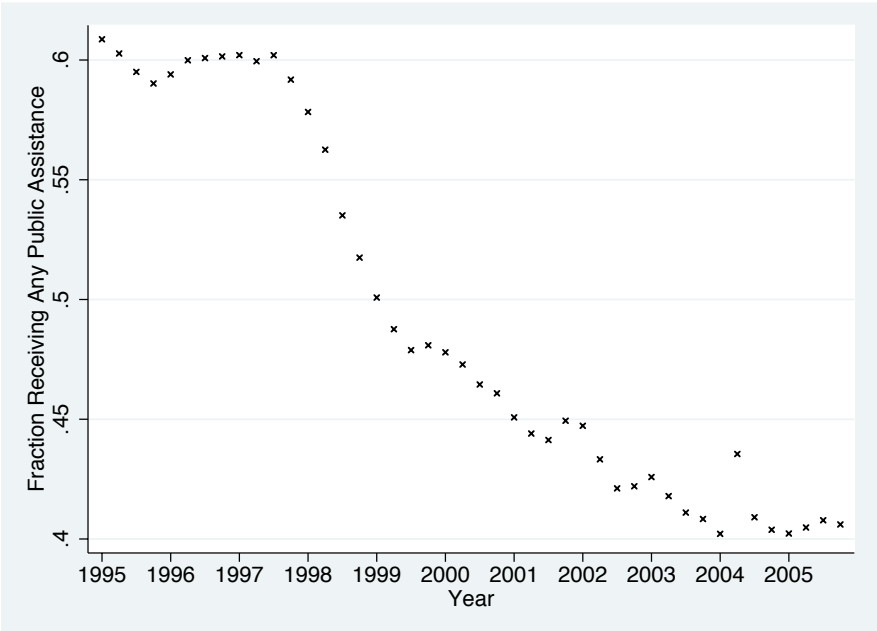

(d) HHH Receiving Any Public Assistance

Notes: Control group defined as CHAC applicants with lottery number greater than 35,000. Sample includes all working-age, able-bodied CHAC applicants who were living in private housing at baseline. 
Appendix Figure II: Chicago Metropolitan Area Vacancy And Unemployment Rates 1995-2005

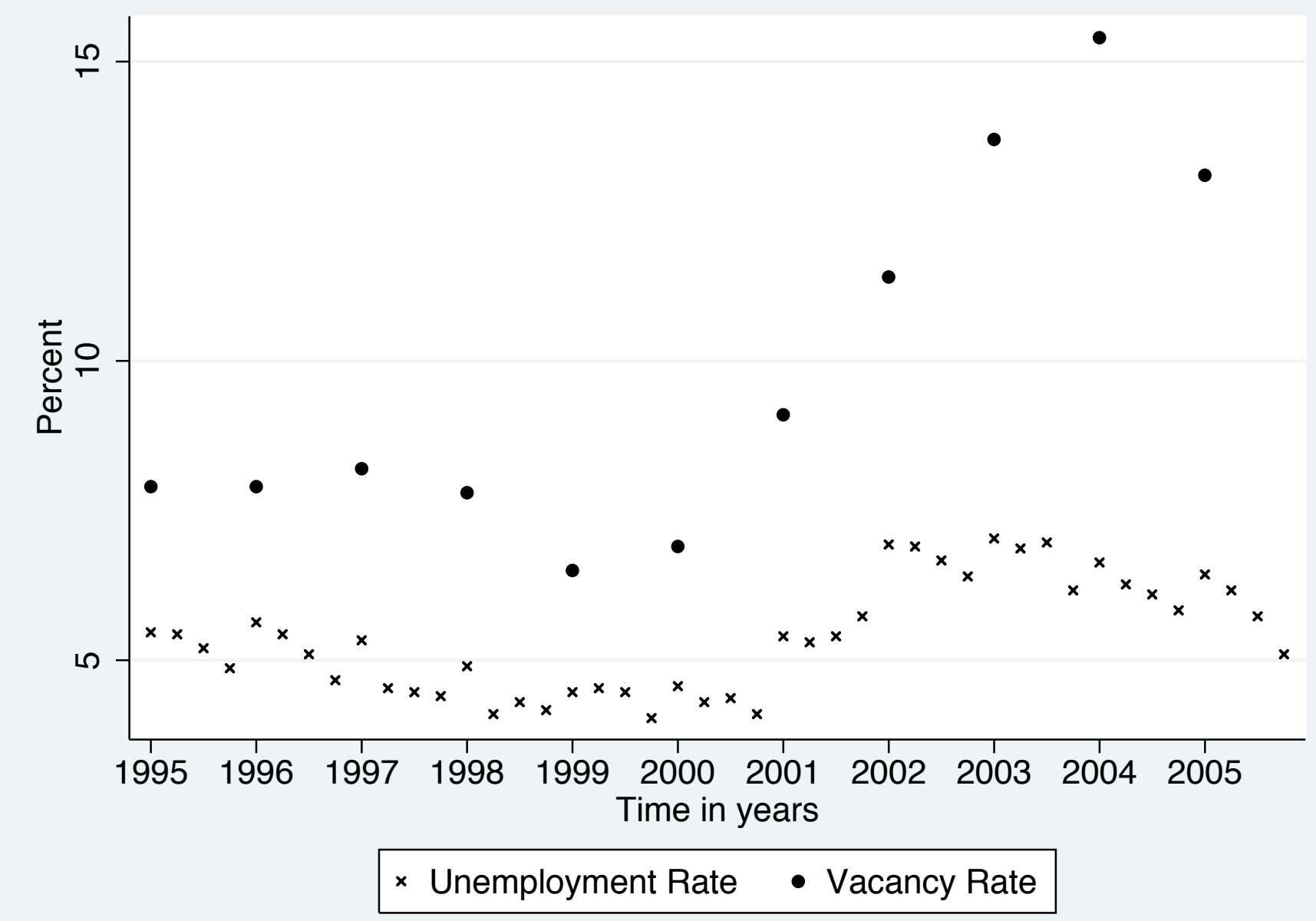

Notes: Unemployment rates, reported quarterly, are taken from http://data.bls.gov/PDQ/outside.jsp?survey=la. Rental vacancy rates, reported annually, are taken from http://www.census.gov/hhes/www/housing/hvs/prevann.html 
Appendix Figure III: Offer And Lease Up Rates Over Time

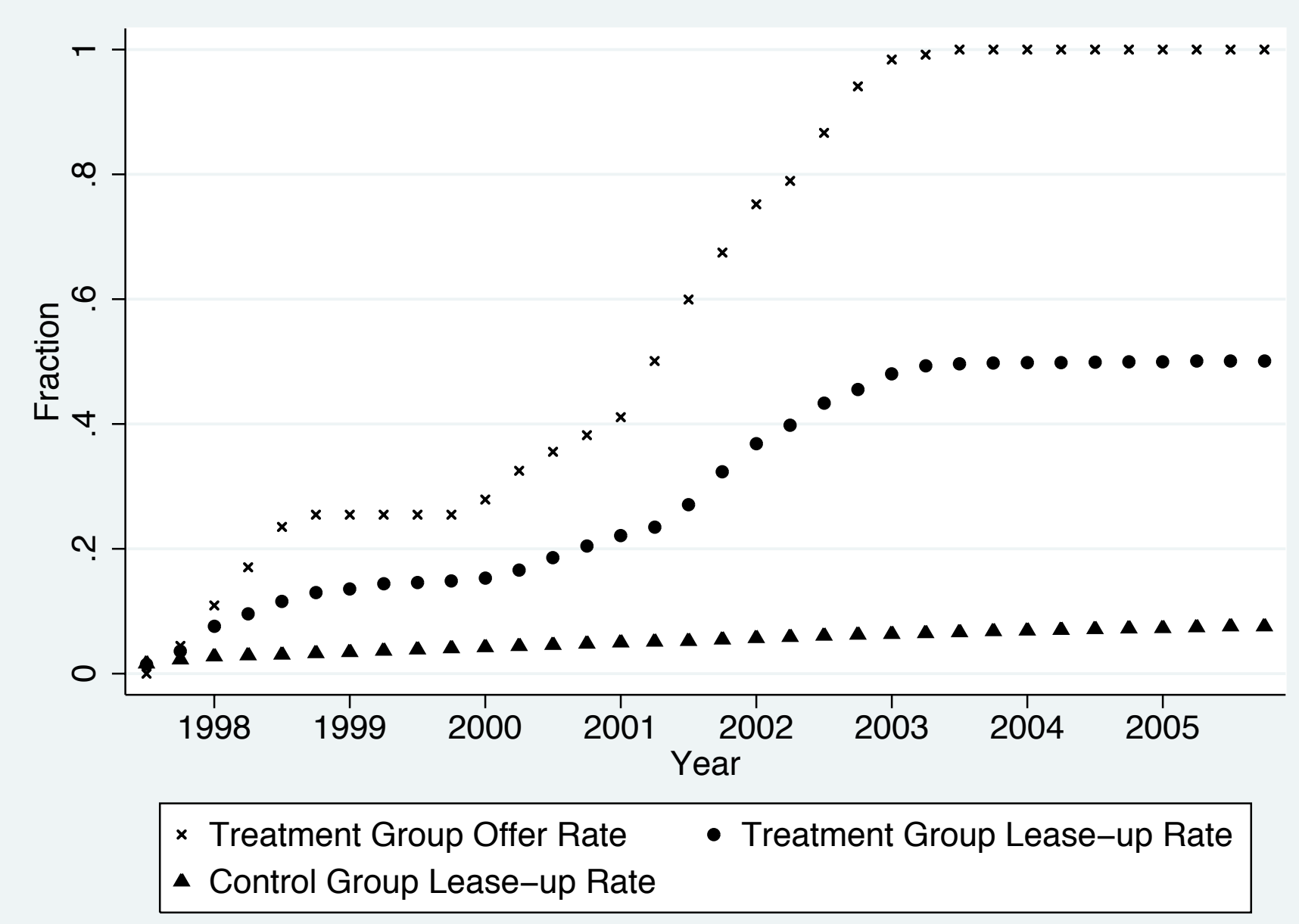

Notes: Treatment group defined as CHAC appicants with lottery number less than or equal to 18,100. Control group defined as CHAC applicants with lottery number greater than 35,000. Sample includes all working-age, able-bodied CHAC applicants who were living in private housing at baseline. 
Appendix Figure IV: ITT Effect Of Vouchers Over Time On Employment And Receipt Of Public Assistance, By Baseline TANF Receipt

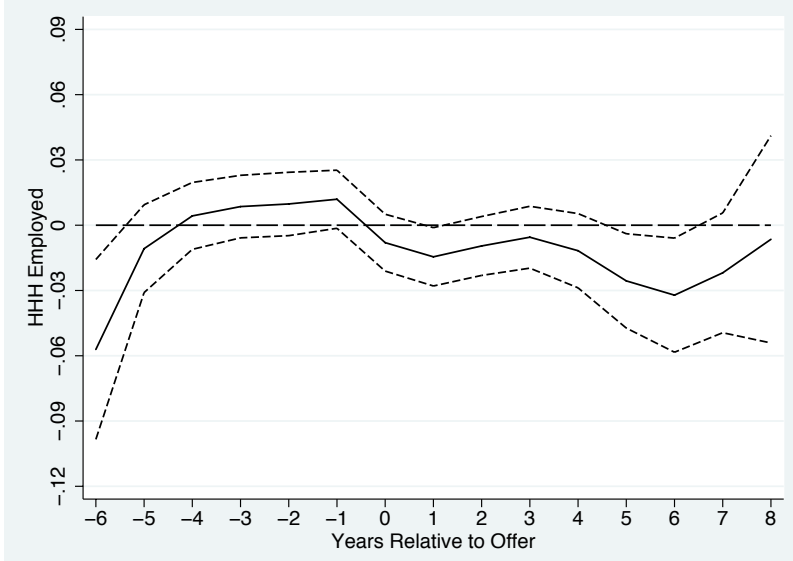

(a) Employment, TANF in 1997 Q2

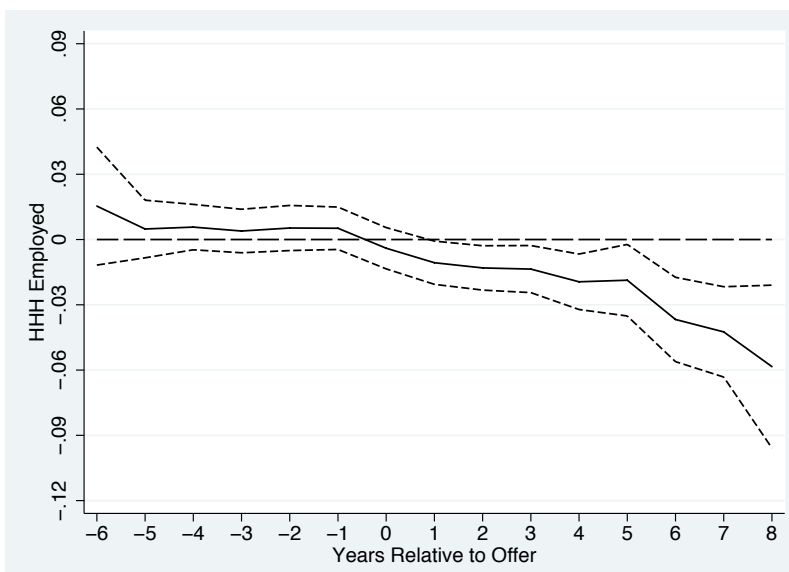

(c) Employment, No TANF in 1997 Q2

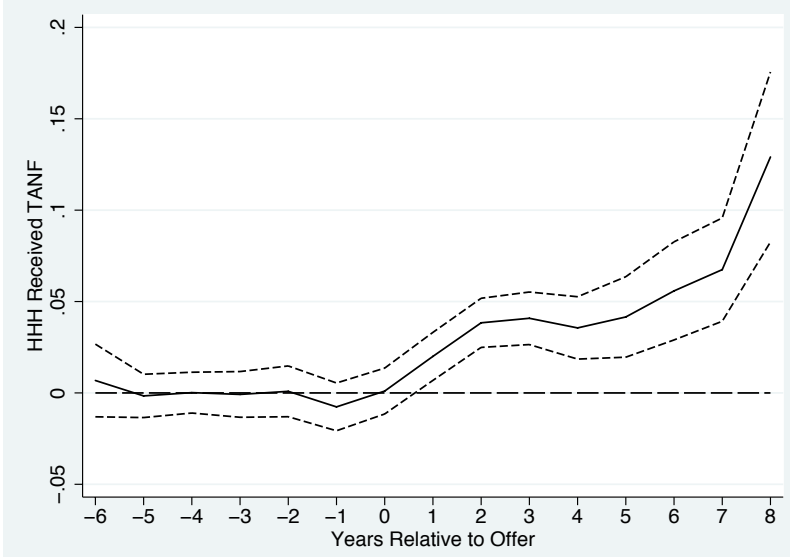

(b) Public Assistance, TANF in 1997 Q2



(d) Public Assistance, No TANF in 1997 Q2

Notes: Dotted lines represent the 95 percent confidence interval. Solid lines represent the point estimate. Estimates come from equation (4) in the text. Year zero is defined as the first full year after an offer, measured at the quarter level, and including the quarter of the offer. The sample for panels (a) and (b) includes all working-age, able-bodied CHAC applicants who were living in private housing and receiving TANF at baseline. The sample for panels (c) and (d) includes all working-age, able-bodied CHAC applicants who were living in private housing and not receiving TANF at baseline. 